\title{
BLUNT BODY NEAR-WAKE FLOW FIELD AT MACH 10
}

\author{
Thomas Horvath ${ }^{*}$
}

and

Klaus Hannemann ${ }^{\dagger}$

\begin{abstract}
$\underline{\text { Abstract }}$
Tests were conducted in a Mach 10 air flow to examine the reattachment process of a free shear layer associated with the near wake of a 70 deg half angle, spherically blunted cone having a cylindrical after body. The nominal free-stream Reynolds number based on model dimeter ranged from $0.25 \times 10^{6}$ to $1 \times 10^{6}$ and the angle of incidence set at 0 and \pm 20 deg. The present study was designed to complement previously reported Mach 6 perfect air tests as well as results obtained in several hypervelocity facilities capable of producing real gas effects. Surface heating rates were inferred from temperature time histories from coaxial surface thermocouples on the model forebody and thin film resistance gages along the model base and cylindrical after body. Limited forebody, base, and support sting surface pressures were obtained with piezoresistive transducers. Experimental results are compared to laminar perfect gas predictions provided by a 3-D Navier Stokes code (NSHYP).

Shear layer impingement on the instrumented cylindrical after body resulted in a localized heating maximum that was 16 to 18 percent of the forebody stagnation point and a factor of 2 higher than laminar predictions, suggesting a transitional or turbulent shear layer.
\end{abstract}

\section{Nomenclature}

$\mathrm{Ch}_{\mathrm{h}} \quad$ Stanton number,

$$
\dot{q} /\left[\mathrm{r}_{\infty} \mathrm{u}_{\infty}\left(\rho \mathrm{h}_{\mathrm{t}}-\mathrm{h}_{\mathrm{w}}\right)\right]
$$

$\mathrm{C}_{\mathrm{p}} \quad 2\left(\mathrm{p}-\mathrm{p}_{\infty}\right) / \mathrm{pu}^{2}$

d diameter, (in.)

h enthalpy, (J/kg)

M free stream Mach number

P pressure, psia

$p_{t, 1}$ tunnel stagnation pressure, $\mathrm{N} / \mathrm{m}^{2}$

$\mathrm{pt}, 2$ free stream pitot pressure, $\mathrm{N} / \mathrm{m}^{2}$

$\dot{q}$ heat transfer rate, $\left(\mathrm{W} / \mathrm{m}^{2}\right)$

$\mathrm{r} \quad$ wall recovery factor

$\mathrm{R}$ radius, (in.)

t time, (sec)

$\operatorname{Re}_{\infty} \quad$ unit free stream Reynolds number,
* Aerospace Technologist, Aerothermodynamics Branch, Aeroand Gas-Dynamics Division, NASA Langley Research Center, Hampton, VA 23681.

$\dagger$ DLR, Institute of Fluid Mechanics, Gottingen, FRG

Copyright $(1997$ by the American Institute of Aeronautics and Astronautics, Inc. No copyright is asserted in the United States under Title 17, U.S. Code. The U.S. Government has a royaltyfree license to exercise all rights under the copyright claimed herein for government purposes. All other rights are reserved by the copyright owner. $\mathrm{ft}^{-1}$

$\mathrm{T}$ temperature, $(\mathrm{K})$

$\mathrm{u}$ velocity, $(\mathrm{m} / \mathrm{sec})$

$\mathrm{x}$ axial distance from model base

$\rho \quad$ density $\left(\mathrm{kg} / \mathrm{m}^{3}\right)$

Subscripts

$\infty \quad$ free-stream conditions

j juncture

m model forebody

n model nose

ref laminar reference heating

s sting

stag reference heating

t reservoir stagnation conditions

w wall

\section{$\underline{\text { Introduction }}$}

Aerobraking as defined by Jones, 1987, involves the use of aerodynamic forces acting on a spacecraft surface to decelerate. One proposed application of this technique for a planetary mission would be the placement of a science payload (Tauber et al., 1993; Mitcheltree, 1994) on or into the planet surface 
following a direct entry from an interplanetary flight.

One aerobraking concept, shown conceptually in Fig. 1, would use a blunt umbrella shaped forebody to provide the aerobraking surface. The spacecraft design for a planetary direct entry approach can be similar. In this mission scenario, the desired payload and/or instrumentation package to be delivered to the surface would be placed behind the aerobrake shell to protect it from the intense heat generated during atmospheric entry. The Mars Pathfinder and Mars 98 missions under the NASA Discovery Program are examples of future planned missions utilizing this type of technology.

The accurate prediction of the near wake flow structure associated with blunt aerobrake concepts is an essential part of the design process as payload size and location are often imposed by wake closure. Proper positioning of the payload would be critical to ensure aerodynamic stability of the spacecraft during entry and to avoid thermal damage from localized near wake phenomenon. Although it is generally recognized that convective heating rates in the base region are low (Gnoffo, 1992), localized increases can occur if the free shear layer that separates from the corner of the aerobraking surface (forebody) impinges on the after body (Gnoffo, 1992; Wells, 1990; Dye, 1993; Hollis, 1996). The successful design of an aerobraking vehicle therefore requires an understanding of the physics associated with hypersonic, blunt-body, near-wake flow fields.

It is recognized that wake flows at supersonic and hypersonic speeds have been studied extensively both experimentally and theoretically since the 1950's. An in depth review of early work and discussions of wake characteristics is provided by Berger, 1971. More recently, Grasso and Pettinelli (1995) have presented an extensive analysis of laminar hypersonic near wake flows. In general, hypersonic near wake flows are characterized by several features which are schematically identified in Fig. 2. The inner or near wake flow consists of a recirculating fluid that is separated from the outer wake flow by a viscous shear layer that originates from the forebody boundary layer. A weak separation or "lip" shock may form (Hama, 1966; Grasso and Pettinelli, 1995) as this boundary layer separates from the surface and becomes a free shear layer. The wake shear layer can be both unsteady and turbulent. As the opposing shear layers converge towards the rear stagnation point (in the absence of a solid surface), the flow is turned through a series of recompression waves which eventually coalesce into a recompression shock. Flow outside of the shear layer dividing streamline continues downstream through a neck region; flow inside of the dividing streamline is turned back towards the base due to recompression. The addition of a solid surface (i.e. support sting) will change the flow; but the salient features remain similar (Wells, 1990).

In 1990, a subgroup of an AGARD fluid dynamics panel (Working Group 18) was formed to address several hypersonic issues, one of which concerned blunt body near wake flow fields. An AGARD Advisory Report edited by Saric et. al. (1996) contains a detailed summary of the working group's activities. One of the stated experimental objectives of the WG-18 subgroup was to characterize real gas effects in the presence of a strongly expanded flow. The wake flow behind a $70 \mathrm{deg}$ blunted cone model was selected by the panel as a test case for investigation and is particularly relevant in light of NASA's new space initiative to Mars.

Experimentally, non-intrusive flow diagnostics such as Planar Laser Induced Fluorescence (PLIF) or Laser Induced Fluorescence (LIF) of NO were to be used to measure rotational temperature in the blunted cone near wake. Surface measurements along the model forebody, base, and support sting were planned to help quantify blunt-body shear layer separation, turning angle, wake establishment/ unsteadiness, and wake closure in the presence of flows exhibiting real gas behavior. The experiments would also serve to help assess and quantify the performance of wind tunnels capable of producing real gas flows. The tests were to be conducted at a common test condition in several of the world's premiere hypervelocity shock tunnels: the piston-driven shock tunnel at DLR-Gottingen (HEG), the Large Energy National Tunnel (LENS), the arc heated hot shot tunnel (F4) located at the Centre du Fauga-Mauzac, and the 42-Inch Shock Tunnel at NASA Ames (deactivated prior to tests). To date, nonintrusive measurements have been attempted at HEG, but with very limited success 
(Rosenhauer, 1994). Fortunately, surface measurements made in these facilities have met with greater success and several continuum high enthalpy experimental and computational studies have resulted (Kastell et. al., 1994, 1995; Holden, 1994; Holden et. al., 1995; Gochberg et. al., 1996). Blunt body computations from Kurotaki (1996), as well as from numerous other authors, can be found in a recently published High Enthalpy Flow Workshop held in Tokyo, Japan.

It was recognized within the AGARD WG 18 activity that along with real gas effects, shear layer transition to turbulence would have a first order influence on the near wake flow field, and in particular, the heating associated with reattachment. Furthermore, the separation of these potential viscous effects from real gas effects would be difficult, if not impossible, to achieve from shock tunnel tests alone (for a given test gas). A brief review of the relevant experimental literature on the subject of shear layer reattachment indicated that the peak heat transfer associated with an impinging transitional shear layer could be much higher than when the separated flow is entirely laminar or turbulent (Baker, 1966). Unfortunately, most blunt-body computational studies in the literature do not address the issue of shear layer transition, but rather focus on forebody transition from laminar to turbulent flow prior to separation (Mitcheltree, 1995; Laurien, 1995). In an attempt to experimentally identify and separate wake viscous effects and wake flow establishment issues from potential real gas effects observed by Kastell and Horvath (1994, 1995), a set of tests (on the same model) was conducted at NASA Langley at Mach 10 and 6 in two conventional low enthalpy blowdown wind tunnels to compliment the high enthalpy, hypervelocity Mach 10 tests conducted by Horvath et. al. at HEG, LENS, and F4. Experimental and computational results from the LaRC Mach 6 perfect air tests have been documented by Horvath and Hannemann (1996).

The purpose of the conventional hypersonic tests at Langley was to obtain both flow field and surface measurements for a fully established wake flow (at Mach 6) in a well characterized uniform free-stream. The objective of this paper is to present surface pressure and heat transfer measurements from tests conducted in the NASA LaRC 31-Inch Mach 10 wind tunnel along with comparisons to laminar prediction.

\section{Apparatus and Tests}

\section{Model Description}

A photograph and dimensioned sketch of the blunt cone model are shown, Figs. 3 and 4, respectively. The 6 -in. diameter $70^{\circ}$ blunted cone forebody was fabricated from Chromel rather than stainless steel to avoid the potential effects of extraneous electro-motive forces (EMF's) resulting from the press fit installation of Chromel-constantan coaxial surface thermocouples into a stainless steel model (Kidd, 1995; Wieting, 1987). The flat model base and 1.5-in. diameter cylindrical support sting were machined from conventional steel and slotted to accept instrumented ceramic (Macor) inserts. Quality assurance measurements on the model were made to verify the accuracy of the surface geometry $( \pm 0.002$-in from nominal) and to precisely locate the individual sensors. The forebody was instrumented with $40 \mathrm{Chromel-constantan}$ coaxial surface thermocouples along a single ray while the base and sting ceramic inserts were instrumented with 65 thin film resistance gages as described by Miller (1981). Coaxial thermocouples were selected for use on the forebody because of their small size, fast response, and durability from particulate damage anticipated during the shock tunnel tests at HEG and NASA Ames.

The uncooled model and support sting were attached to the facility support barrel, Fig. 5, approximately 2 model diameters downstream in an attempt to maintain set-up consistency between all tests performed on this model. Model angle of incidence was 0 and \pm 20 deg. The entire assembly was injected into the tunnel centerline from a shielded and retracted position in approximately 0.6 seconds

\section{Facility Description}

The model was tested in the 31-Inch Mach 10 Air Tunnel at the NASA Langley Research Center. A detailed description of this facility and related instrumentation is presented by Miller (1992). The 31-Inch Mach 10 is a blowdown facility which uses dried, heated, and filtered air as the test gas. Typical 
operating conditions for the tunnel are stagnation pressures ranging from 150 to 1350 psia and stagnation temperatures from 1350 to $1450{ }^{\circ} \mathrm{F}$ yielding free stream unit Reynolds from 0.25 to $2 \times 10^{6} / \mathrm{ft}$. It has a closed 31 - by 31-in. test section with a contoured threedimensional water-cooled nozzle to provide a nominal free stream Mach number range from 9.6 to 10 . A hydraulically operated model injection mechanism can inject the model into the flow in 0.6 seconds. The maximum run time for this facility is approximately 1 minute; typical run times for the heat transfer and pressure measurements for this test series were 5 seconds.

\section{Instrumentation. Data Reduction, and Uncertainty}

The reservoir pressure $p_{t, 1}$ was measured with two silicon sensors having a full scale rating of 500 psia or 2500 psia, depending on the operating condition of the tunnel. The reservoir temperature $T_{t, 1}$ was measured with two iron-constantan thermocouples inserted through the wall of the settling chamber. Test section wall static and pitot pressures were monitored and compared to tunnel empty conditions to assess model blockage effects. Differences in pitot pressure of less than 0.6 percent were measured and it was concluded that significant blockage did not exist. The ratio of projected model frontal areato-tunnel cross sectional area for the present test was 0.029 . A 16-bit analog-to-digital acquisition system acquired the data on all channels at a rate of 50 samples per second.

Forebody surface temperature measurements were obtained from commercially available 0.031-in. diameter Chromel-constantan coaxial surface thermocouples that were press fit into the model wall. The model contoured junction was formed at the sensing surface by blending (lightly sanding) the two materials together. Several thermocouples had a second junction that was used to monitor the backside wall temperature in order to assess conduction effects. A general description of the coaxial thermocouple and its use is outlined by Kidd et. al. (1995).

The more sensitive thin film resistance gage was used to measure surface temperature in the base and wake regions. Standard mechanical deposition techniques developed at LaRC (Miller, 1981) were used to fabricate the 0.030-in. by 0.040 -in. platinum sensing element. Surface temperatures were integrated over time to determine the local heat transfer rate using the computer code developed by Hollis (1995). Both analytical (Cook, 1970; Kendall-Dixon, 1967) and numerical finitevolume heat transfer models are incorporated into this code. The analytical solutions are derived from one-dimensional, semi-infinite solid heat conduction theory with the assumption of constant substrate (model) thermal properties. When using the analytical option the inferred heating rates are empirically corrected for the effects of variable model thermal properties. The finite-volume technique, which was used for the present tests, directly accounts for the variable model thermal properties (results from recent laboratory tests to determine substrate thermal properties have been incorporated into the code; Hollis, 1995). This option also removes the restriction of a semi-infinite wall boundary condition. This was an important consideration for this study as the model was designed and instrumented primarily for impulse facility testing where test times are on the order of milliseconds and the semi-infinite wall assumption is valid. In contrast, test times in the conventional hypersonic wind tunnels at LaRC were several orders of magnitude longer and led to invalidation of this assumption. For the present study, the uncertainty associated with variable wall thermal properties is believed to be minimal, particularly in the wake region where surface temperature increases of $15^{\circ} \mathrm{K}$ or less were measured.

A typical temperature and $\mathrm{C}_{h}$ time history for a thin film sensor located at the stagnation point and along the support sting in the wake region is shown in Figs. 6 a-b. Unlike shock tunnel data where wake flow establishment times must be determined, the local Stanton number remains essentially constant upon reaching the tunnel centerline.

$$
\text { Commercially available 0.064-in. }
$$
diameter, temperature compensated, piezoresistive pressure transducers were flush mounted with the model surface. The transducers were statically calibrated with methods traceable to NBS standards over the 
expected range of pressures and temperatures. The two forebody transducers were rated at 25 psia full scale while the two transducers located on the base and sting were rated at 2 psia FS. The results from the static calibrations indicated that the combined effects of nonlinearities and hysteresis was less than 1 percent of FS. Daily in-situ tunnel calibrations were performed to monitor the performance of the sensors.

Measured values of $P_{t, 1}$ and $T_{t, 1}$ are believed to be accurate to within \pm 2 percent. Based on previous results (Hollis, 1996), the heat transfer measurements are believed to be accurate to within \pm 8 percent. Repeatability for the forebody and wake heat transfer measurements was found to be generally better than \pm 1 and 2 percent, respectively.

\section{Prediction Method}

The NSHYP code has been developed at DLR for the computation of supersonic and hypersonic flows of a perfect gas or a chemically reacting mixture of perfect gases (see Brenner et al., 1993; Brenner and Prinz, 1992; Riedelbauch and Brenner, 1990). Many hypersonic flow fields of interest permit the use of the thin-layer Navier-Stokes equations. However, due to the large recirculation region which develops in the wake of the blunted cone, the basic equations under consideration here are the full unsteady Navier-Stokes equations for a body-fitted coordinate system ( $\xi$ : streamwise; $\eta$ : circumferential; $\zeta$ : wall normal coordinate),

$$
\frac{\partial \hat{U}}{\partial t}+\frac{\partial \hat{E}}{\partial \xi}+\frac{\partial \hat{F}}{\partial \eta}+\frac{\partial \hat{G}}{\partial \zeta}=\frac{1}{\operatorname{Re}_{\infty, r}} \cdot\left[\frac{\partial \hat{E}_{v i s}}{\partial \xi}+\frac{\partial \hat{F}_{v i s}}{\partial \eta}+\frac{\partial \hat{G}_{v i s}}{\partial \zeta}\right]
$$

where

$$
\hat{U}=J^{-1}(\rho, \rho u, \rho v, \rho w, e)^{T}
$$

The inviscid and viscous fluxes are denoted by $\hat{E}, \hat{F}, \hat{G}$ and $\hat{E}_{v i s}, \hat{F}_{v i s}, \hat{G}_{\text {vis }}$ respectively. The transformed vector of the conservative variables is given by $\hat{U}$; here $\mathrm{J}^{-1}$ represents the jacobian of the transformation matrix. The equations have been nondimensionalized using the free stream density, velocity and viscosity, and the radius of the blunted cone. For perfect gas computations the viscosity coefficient, $\mu$, and the coefficient of thermal conductivity, $\kappa$, are calculated from the Sutherland law. The Prandtl number is assumed to be constant and equal to 0.71 . The thermodynamic properties of pressure and temperature are calculated from the conservative variables using the thermal and caloric state equation of perfect gas with the ratio of specific heats for diatomic gases $(\gamma=1.4)$.

The time discretization is fully implicit in order to avoid stiffness problems introduced by the small mesh increments in the boundary layer. NSHYP was primarily designed for the computation of steady flow fields. Therefore, the time integration was chosen to be of first order accuracy, as only the converged steadystate solutions are of interest. The spatial derivatives of the inviscid fluxes are approximated by a second order upwind Total Variation Diminishing (TVD) formulation according to Yee and Harten (1987), and the spatial derivatives of the viscous fluxes are discretized by second order central differences. The TVD flux-difference splitting algorithm involves the solution of locally one-dimensional Riemann problems at the cell interfaces. Here the approximated Riemann solver of Roe (1981) is applied. Introducing a line Gauss-Seidel relaxation results in a linear system of blocktridiagonal matrices which is solved with the Richtmyer algorithm.

The physical domain considered here is bounded by the body, the inflow and outflow boundary and the line of symmetry. On the body no-slip conditions apply. The temperature of the isothermal wall is set to $\mathrm{T}_{\mathrm{wall}}=300 \mathrm{~K}$. The momentum equation in wall-normal direction is approximated by $\partial \rho / \partial \mathrm{n}=0$ at the wall. At the inflow boundary a homogeneous supersonic flow is assumed. The free stream conditions are given in Table 1. At the outflow boundary the conservative variables are extrapolated from the integration domain by assuming that their slope in the $\mathrm{x}$-direction is constant, i.e. $\mathrm{d}^{2} \mathrm{U} / \mathrm{d} \xi^{2}=0$. In order to compute axisymmetric flows with the present $3 \mathrm{D}$ code, appropriate symmetry conditions were employed to evaluate the fluxes in circumferential direction. At the line of symmetry, which for axisymmetric flows 
represent a singularity, the variables were determined by means of a cubic extrapolation.

Grid description and sensitivity studies will be deferred to the discussion of the comparisons of measurement with prediction.

\section{Test Conditions}

Tests were performed at Mach 10 at $\alpha=0$ and $\pm 20 \mathrm{deg}$ in air for nominal reservoir pressures and temperatures shown in Table 1. The nominal free stream Reynolds numbers based on model diameter for these conditions were $0.25 \times 10^{6}, 0.5 \times 10^{6}$, and $1 \times 10^{6}$.

\section{$\underline{\text { Results and Discussion }}$}

The data presented in the subsequent sections are organized and presented in the following manner: (1) surface heating distributions along the model forebody, base, and support sting are presented in the form of a normalized Stanton number, $\mathrm{C}_{\mathrm{h}} / \mathrm{C}_{\mathrm{h}}$, stag where $\mathrm{C}_{h}$, stag corresponds to the measured stagnation point heating on the model forebody unless otherwise noted; (2) limited pressure measurements on the forebody, base, and sting are presented in the form of a pressure coefficient, $\mathrm{C}_{\mathrm{p}}$; (3) comparisons with laminar predictions along the forebody, base, and sting are made in the form of Stanton number, $\mathbf{C}_{\mathbf{h}}$; (4) Comparisons with laminar pressure predictions are made.

\section{Surface Heating}

Typical run-to-run repeatability of the measured unnormalized Stanton number heating distribution is shown in Figs. 7 a-b for the $\operatorname{Re}_{\infty, d}=0.5 \times 10^{6}$ condition. Differences of less than 1 percent and 2 percent were measured on the forebody and sting, respectively. Normalized Stanton number surface heating distributions at $\mathrm{a}=0 \mathrm{deg}$ along the forebody, base, and sting are shown over the range of Reynolds numbers, Figs. 8 a-b, 9 $a-b$, and $10 a-b$.

As expected, the forebody heating rapidly diminishes as the flow accelerates around the spherical nose and onto the conic section. Heating over the cone section averaged approximately 60 percent of the forebody stagnation point heating level, Figs. 8a, 9a, and 10a. As the boundary layer expands and thins as it approaches the forebody shoulder, the rate at which the heating decreases is moderated and then quickly falls off as the boundary layer separates from the base and forms the free shear layer. The expected local heating peak on the model shoulder was not identified due to minimal sensor resolution in this area.

The near wake recirculation region, which is bounded by the free shear layer, displayed characteristic low levels of surface heating. For example, heating on the model base at $\mathrm{S} / \mathrm{Rn}=3$ remained below 1 percent of the forebody stagnation point heating level, Figs. $8 \mathrm{~b}, 9 \mathrm{~b}$, and 10b. The characteristic local peak associated with the shear layer reattachment on the sting is evident further downstream $(\mathrm{S} / \mathrm{Rn}=9)$ and was 16 and 18 percent of the measured forebody stagnation point heating rate at the low and high Reynolds numbers, respectively. These wake peak heating levels were also measured by Dye (1993) on a similar $70 \mathrm{deg}$ sphere cone tested in the same facility. However, subsequent shock tunnel data (Holden, 1995) obtained on the present blunted cone configuration and corresponding laminar predictions from Moss (1995) imply that peak heating associated with laminar wake shear reattachment is typically 5-6 percent of the forebody stagnation point heating. One explanation for the differences observed between tests in the 31-Inch Mach 10 Tunnel and LENS is that the relatively higher LaRC wake heating was produced by a non-laminar reattachment process.

The influence of Reynolds number on normalized base-sting heating distributions is more clearly shown, Fig. $11 \mathrm{~b}$, where a small, but measurable spatial displacement and an increase in magnitude of the heating peak associated with the reattachment process is observed. A factor of 4 increase in Reynolds number produced a forward shift (towards the model base) of the peak from $\mathrm{S} / \mathrm{Rn}=9.4$ to 8.8 with a corresponding 8 percent increase in peak heating. These same trends were noted by Hollis (1996) and Wells (1990) while conducting similar blunt body wake studies in the same Mach 10 wind tunnel. The upstream movement suggests a decrease in the size of the wake recirculation vortex and/or thickening of the shear layer. Although it is recognized that the heating peak generally does not coincide with the actual reattachment point, experimentally 
obtained surface streamline patterns (not shown) indicate an upstream movement of the attachment point as well.

Berger (1971) discussed several wake flow models that suggest the size of a laminar wake recirculation region should actually increase with increasing Reynolds number. The present Mach 10 wake heating trends imply that wake shear layer transition has occurred prior to reattachment/recompression. This would confirm speculation by Holden (1995) that differences in measured wake heating levels from a broad range of AGARD WG 18 blunt-body tests could result from differences in the turbulent structure of the shear layer.

Normalized forebody heating distributions, Fig. 11a, showed little (less than 6 percent) effect of Reynolds number and were within the experimental uncertainty.

The effect of angle-of-attack on forebody and base-sting Stanton number heating distributions are shown, Figs. 12 a-b. The 70 deg half angle cone model was pitched $\pm 20 \mathrm{deg}$ to obtain windside $(-20 \mathrm{deg})$ and leeside $(+20$ deg) heating (it is noted that within the proposed Mars Microprobe and Stardust programs such high angle-of-attack profiles are being addressed for blunt body planetary entry). At such extreme angles-of-attack, the location of the forebody stagnation point and the associated subsonic region can become very sensitive to local conditions and subtle changes in angle-of-attack. On the forebody, Fig. 12a, the geometric stagnation point is found on the axis of symmetry located at $\mathbf{S} / \mathbf{R n}=0$. At $a=0$ deg, the peak heating point on the model and the geometric stagnation point are coincidental as expected. At angle-of-attack the peak heating point on the model has moved away from the geometric stagnation point to a point on the conical surface. Computations by Weilmuenster and Hamilton (1986) on a similar 70 deg blunted cone in air at $\alpha=20 \mathrm{deg}$ predict this behavior.

At angle-of-attack, the heating on the forebody conical surface $(\mathrm{S} / \mathrm{Rn}=1)$ increased by 30 percent on the more windside surface (shown $\alpha=-20 \mathrm{deg}$ ) and decreased by 33 percent on the more leeside surface (shown $\alpha=$ $+20 \mathrm{deg}$ ). At $\alpha=-20 \mathrm{deg}$ the ray of thermocouples on the conical surface is perpendicular to the flow with the stagnation heating point lying near $S / R n=1$. Away from this general location the heating eventually increases as the flow moves towards and accelerates around the spherical nosecap and the forebody shoulder. The localized heating plateau observed in the present study near $\mathrm{S} / \mathrm{R} n=1$ has been reported in the literature. Shimshi (1990), Reddy and Miller (1986), Stewart and Chen (1994), and a Project Viking data report (Faye-Petersen, 1972) contain high angle-of-attack blunted cone experimental heating distribution trends similar to that observed in this study.

Over this same angle-of-attack range the location of peak heating found on the sting in the wake region, Fig. $12 \mathrm{~b}$, moved upstream from $S / R n=9.2$ at $\alpha=0$ deg to $S / R n=5.7$ at $\alpha=-20$ deg. At the same time the magnitude was increased by over a factor of 2. Additionally, the heating to the model base (where instrumentation packaging would likely be located) was increased by 2.5 times that measured at $\alpha=0$ deg. As anticipated, $\alpha=+20$ deg presented a leeside flow and reduced the base-sting heating.

\section{Surface Pressure}

Typical run-to-run repeatability of the pressure coefficient, $\mathrm{C}_{\mathrm{p}}$, is shown, Fig. 13, for the $\operatorname{Re}_{\infty, \mathrm{d}}=1.0 \times 10^{6}$ condition where differences of less than 1 and 4 percent were measured on the forebody and base, respectively. As expected, the pressure coefficient is invarient with Reynolds number as shown in Fig. 14. A semi-log axis is utilized because of the large range between coefficients on the forebody and base/sting.

\section{Computational Predictions}

\section{Grid Sensitivity}

The present computational results and those obtained earlier by Horvath and Hannemann (1996) and Hollis (1996) indicate the necessity of grid refinement studies to examine the sensitivity of the wake flow field and associated surface heating to grid spacing and alignment. The topology of the nominal single block grid used in the present computations is shown, Fig. 15.

In order to investigate the dependence of the solution on grid resolution, four grids containing $771 \times 301,386 \times 151,193 \times 76$, and $97 \times 38$ points in wall tangential and wall normal direction, respectively, were used. The 
finest grid was first generated using the elliptic grid generator MEGACADS (Ronzheimer et. al. 1994). For this grid, the distance of the first grid line to the wall normalized to the radius of the forebody was $3 \times 10^{-6}$. The remaining three grids were obtained by removing every second grid point in each direction.

The effect of grid refinement on surface heating for $\mathrm{Re}_{\infty, \mathrm{d}}=0.28 \times 10^{6}$ is summarized in Figs. 16 a-b. The discussion of grid convergence is restricted to the effect on surface heating distributions as flowfield quantities were not measured. The computed surface heat transfer along the forebody, Fig. 16a, displayed little influence to grid refinement.

Wake heating calculations were more sensitive to grid refinement. The predicted surface heating along the base-sting obtained with the four grid sizes is shown, Fig. 16b. The solution obtained with the $771 \times 301$ grid indicated the magnitude of the heating peak associated with the reattaching shear layer was reduced 8 percent relative to predictions with the $386 \times 151$ grid and the location was displaced downstream. These findings are similar to grid refinement observations by Hollis (1996). Particle traces, shown in Figs. 17 a-d, associated with the range of grid densities for $R e_{\infty, \mathrm{d}}=0.28 \times 10^{6}$, reveal the complexity of the predicted wake flowfield. These particle traces were obtained by integration of the steady velocity field. All grid densities appeared to resolve a system of three vortices within the base recirculation region. The computed location of the small vortex found just behind the model shoulder moved closer to the shoulder as grid density was increased. The effect of this movement is illustrated by the trends in heating found at this location ( $\mathrm{S} / \mathrm{Rn}=3)$, Fig. $16 \mathrm{~b}$.

In addition to the effects of grid refinement on surface heating, the sensitivity of the base flowfield to model support interference was also computationally investigated. As far as this author is aware, all blunt body predictions in support of the AGARD WG 18 activity have been carried out under the premise of a constant diameter support sting. In actuality, the model and sting were supported in the tunnel by a larger diameter support barrel located approximately 2 model diameters downstream from the model base (see photo Fig. 5). Speculation persisted that the factor of 3 difference between measurement and laminar predictions (Horvath and Hannemann, 1996) at Mach 6 along the sting could be the result of interference from this support barrel which was not modeled computationally. To address these concerns for the present results, predictions were made which modeled the support hardware more appropriately. The influence of the model support system on predicted sting Stanton number heating distribution is shown, Fig. 18. The small differences in prediction are believed to be grid related. The extension of the grid to include the support barrel resulted in an inadvertant shifting of grid points tangential to the wall. Because of the wake grid sensitivity identified earlier, this 'effective' grid alteration may explain the small differences in prediction. It is concluded that large scale interference effects are not present at the measurement stations on the model.

Based on the present grid sensitivity study it has been concluded that converged forebody solutions have been achieved. Utilizing the present grid topology and grid densities, the wake heating solutions remained sensitive to grid refinement. A comprehensive wake grid sensitivity study by Hollis (1996) revealed that because the free shear layer and wake are viscous dominated regions, grid spacing comparable to that found in an attached wall boundary-layer was required to properly resolve the wake flow field. Equally important, it was found that grid alignment with the flow was a concern. Hollis concluded that lack of resolution in the shear layer along with skewness of the grid lines with respect to the flow direction had the net effect of introducing a form of artificial viscosity into the computations. This ultimately was shown to effect the size and shape of the recirculation region and alter the magnitude of the sting heating. Although not as comprehensive as Hollis, the present grid refinement study did yield the same trends and conclusions. That is, the location of the heating peak found on the sting was displaced futher away from the model base as grid density was increased while the magnitude of the heating decreased 8 percent between the two finest grids. It is recommended that future blunt body wake heating predictions be performed with a grid 
topology that captures the wake shear layer more appropriately (Hollis, 1996).

\section{Comparisons to Measurement}

\section{Surface Heating}

Comparisons of surface heating predictions obtained with the $386 \times 151$ grid to measurements along the model forebody and base-support sting at $\alpha=0$ deg are shown in Figs. $19 \mathrm{a}-\mathrm{b}, 20 \mathrm{a}-\mathrm{b}$, and $21 \mathrm{a}-\mathrm{b}$ for $\operatorname{Re}_{\infty, \mathrm{d}}=0.25 \times 10^{6}, 0.5 \times 10^{6}$, and $1 \times 10^{6}$, respectively. Error bars placed on the data of \pm 8 percent are based on an analysis by Hollis (1996).

On the forebody, Figs. 19a, 20a, and 21a, the best agreement was found at the stagnation point $(\mathrm{S} / \mathrm{Rn}=0)$ and along the cone section prior to the shoulder $(1.5<\mathrm{S} / \mathrm{Rn}<2)$. The largest disparity between measurement and laminar prediction was consistently on the cone section between $\mathrm{S} / \mathrm{Rn}=0.2$ and 1.5. While the predictions were generally within the stated experimental uncertainty for the lowest two Reynolds numbers, Figs. 19a and 20a, the computations underpredicted the Stanton number distribution at the highest Reynolds number case, Fig. 21a (7.7 percent difference at the stagnation point). At this higher Reynolds number it is possible, although very unlikely, the forebody boundary layer was approaching a transitional state as was the case observed at Mach 6 by Horvath and Hannemann (1996). Because the numerical grid was fixed for all three Reynolds numbers it could also be argued that the allocation of grid points within the thinner forebody boundary layer at this Reynolds number was inadequate. As the cell Reynolds number at the wall was below one for all three cases and it is believed that this was not a concern.

Spatial resolution of the heat transfer gages in the vicinity of the model shoulder was not sufficient to resolve the local peak in heating observed computationally at $\mathrm{S} / \mathrm{Rn}=2.04$.

The laminar calculations in the near wake indicated that the heating peak associated with reattachment was approximately 50 to 55 percent below the measured values, Figs. 19b, 20b, and 21b. This is consistent with the assumption of a transitional/turbulent reattaching shear layer, where the magnitude of the heating peak would be larger relative to the laminar counterpart.

The hypersonic wake transition work of Lees (1964) correlated a large range of ground and flight test data in an attempt to predict laminar-turbulent shear layer transition. It was concluded that for a blunt body in hypersonic equilibrium flow the observed transition Reynolds number based on local edge conditions was on the order of $10^{5}$ for an edge Mach number of approximately 2.5. In this study, at the origin of the free shear layer where the boundary layer separates from the forebody, the computed edge Mach number was equal to 3.1 and did not vary with Reynolds number. The corresponding predicted edge Reynolds numbers varied from $0.2 \times 10^{5}$ to $0.6 \times 10^{5}$. This would suggest the free shear layer transition could indeed occur prior to reattachment.

These findings are consistent with those made by Horvath and Hannemann (1996) at Mach 6 where intrusive measurements revealed a blunt body turbulent wake shear layer. This trend was also recently documented experimentally by Hollis (1996) who, in the same wind tunnel with a smaller diameter blunted cone model, was able to achieve both laminar and turbulent wake heating measurements. Hollis found the peak sting heating was 8 percent of the forebody stagnation value at the lowest Reynolds number condition $\left(\operatorname{Re}_{\infty, \mathrm{d}}=0.08 \times 10^{6}\right)$, implying a laminar reattachment. The heating peak ratio increased to 15 percent at the highest Reynolds number condition, suggesting a transitional/turbulent shear layer. For the present study the predicted laminar heating peak found downstream on the sting varied with Reynolds number (not shown) and was 6-8 percent of the predicted forebody stagnation point heating. The corresponding experimental results varied from $16-18$ percent.

On the model base, the predicted heating was generally four times that measured. It is assumed the two local heating peaks determined computationally at $\mathrm{S} / \mathrm{Rn}=2.3$ and 2.85 are the result of flow stagnation associated with the predicted vortices located near the shoulder and base-sting juncture, Figs. 17 a-d. Interestingly, these local heating peaks were not measured experimentally in the present study at Mach 10 as they were at Mach 
6 (Horvath and Hannemann, 1996). The lack of the first peak at $\mathrm{S} / \mathrm{Rn}=2.3$ may suggest a fundamental difference between experiment and prediction in the separation process found at the vicinity of the model shoulder which would ultimately affect the development of the wake vortex structure downstream. The lack of experimental evidence of the second peak at $\mathrm{S} / \mathrm{R} n=2.85$ suggests that the predicted laminar base-sting juncture vortex: (1) is not present, (2) has undergone significant viscous dissipation due to a turbulent wake structure, or (3) is highly unsteady and its position cannot be determined with the mean heating measurement. Rigorous validation of the complex recirculation patterns predicted near the base-sting juncture were not possible, as low data sampling rates and/or lack of surface instrumentation in the desired locations prevented further analysis.

\section{Surface Pressure}

Comparisons of laminar surface pressure predictions obtained with the $386 \times 151$ grid to measurements along the model forebody and base-support sting at $\alpha=0$ deg are shown in Figs. 22 a-c for $\operatorname{Re}_{\infty, d}=0.25 \times 10^{6}, 0.5 \times 10^{6}$, and $1 \times 10^{6}$, respectively. The predicted pressure distribution is well within the experimental uncertainty at the two forebody measurement stations at all Reynolds numbers. The predicted wake pressures on the model base $(\mathrm{S} / \mathrm{R} n=3.1)$ and downstream on the support sting $(\mathrm{S} / \mathrm{Rn}=9.7)$ are generally low relative to the measurements. At the two lowest Reynolds numbers the predicted model base pressures are just within the experimental uncertainty. Downstream of the reattachment point, the laminar calculations underpredict measurement by 16 and 35 percent at the highest and lowest Reynolds numbers, respectively. As with the heating comparisons, one possible explanation may be that the calculations were performed assuming a laminar wake flow structure. If the wake structure is indeed transitional or turbulent as believed, then higher pressures may result from additional compression from a larger shear layer turning angle (smaller wake vortex) and a more direct impingement of the shear layer on the sting.

\section{Concluding Remarks}

The reattachment process of a free shear layer associated with the near wake of a bluntbody was experimentally and computationally investigated at Mach 10 in air over a freestream Reynolds number range based on body diameter of $0.25 \times 10^{6}$ to $1 \times 10^{6}$ at $\alpha=0 \mathrm{deg}$ and \pm 20 deg. The study was designed to complement previously reported Mach 6 perfect air tests as well as results obtained in several hypervelocity shock tunnels capable of producing real gas effects. The configuration consisted of a 70 deg half angle, spherically blunted cone, with a rounded shoulder, flat base, and a cylindrical afterbody. Surface heating rates were inferred from temperature time histories measured with coaxial surface thermocouples on the model forebody and with thin film resistance gages along the model base and cylindrical after body. Surface pressure was measured by piezoresistive transducers. Perfect gas laminar numerical simulations were provided by a 3-D Navier Stokes code (NSHYP) utilizing a single block grid topology.

The magnitude and position of the peak heating on the sting is sensitive to the state (i.e. laminar/turbulent) of the wake free shear layer. Measured peak heating due to shear layer impingement on the instrumented cylindrical after body was found to be over a factor of 2 higher than laminar predictions and resulted in a localized heating maximum that was 16 percent to 18 percent of the forebody stagnation point heating. An increase in Reynolds number produced an increase in magnitude and forward movement (towards the base) of the wake heating maximum on the support sting; this behavior is indicative of a turbulent wake structure. These findings are consistent with those for Mach 6 air (Horvath and Hanneman, 1996) where schlieren images, intrusive wake pitot pressure, and hot wire surveys were used to establish the state of the wake free shear layer.

Computationally, it was found that the grid densities examined in this study were more than adequate to yield converged forebody heating solutions. The laminar wake heating predictions could be improved by aligning the grid with the wake free shear layer and reallocating more points within the recirculation region and shear layer. The present benchmark data set is being used to challenge 
transition and turbulence models that are appropriate to blunt body wake flow fields.

\section{Acknowledgments}

Without the assistance of the following individuals this work would not have been possible: Ed Self, Steve Parrish, Greg Draughon and Doug Grizzle for model fabrication/instrumentation support; Larry Murray, Christal Kellam, and Jeff Werner for wind tunnel support; Sheila Wright for data acquisition assistance; Brian Hollis, Scott Berry, Brent Ross, Monika Hannemann, and Dirk Kastell for data/CFD analysis support; and, Richard Wheless for documentation assistance. The authors gratefully acknowledge their contributions and behindthe- scenes work.

\section{$\underline{\text { References }}$}

Baker, P. J. and Martin, B. W. (1966): Heat Transfer in Supersonic Separated Flow Over A Two-Dimensional BackwardFacing Step. International Journal of Heat Mass Transfer, Vol. 9, p. 1081-1088.

Berger, Stanley A. (1971): Laminar Wakes. American Elsevier Publ., Inc.

Brenner, G. and Prinz, U. (1992): Numerical Simulation of Chemical and Thermal Nonequilibrium Flows after Compression Shocks. AIAA 27th Thermophysics Conference, July 6-8, Nashville, TN, AIAA 92-2879.

Brenner, G.; Gerhold, T.; Hannemann, K.; and Rues, D. (1993): Numerical Simulation of Shock/Shock and Shock-Wave/BoundaryLayer Interactions in Hypersonic Flows. Computers Fluids, Vol. 22, No. 4/5.

Cook, William J. (1970): Unsteady Heat Transfer Measurements to a Semi-Infinite Solid With Arbitrary Surface Temperature History and Variable Thermal Properties. Iowa State Univ. Tech Report ISU-ERIAMES-67500.

Dye, T. P. (1993): An Experimental and Computational Investigation of the Flowfield About An Aeroassisted Space Transportation Vehicle at Mach 10. M. S. Thesis, University of Tennessee, Knoxville.

Faye-Petersen, R. (1972): Heat Transfer and Pressure Distributions at $\mathrm{M}=8$ on 0.029 Scale Models of the Viking Entry Vehicle. NASA CR-132413, (Contract NAS1-9000).

Gochberg, L. A.; Allen, G. A.; Gallis, M. A.; and Deiwert, G. S. (1996): Comparison of Computations and Experiments For Nonequilibrium Flow Expansions Around A Blunted Cone. AIAA 34th Aerospace Sciences Meeting, Jan. 15-18, Reno, NV, AIAA 96-0231. 
Gnoffo, P. A.; Price, J. M.; and Braun, R. D. (1992): Computation of Near-Wake, Aerobrake Flowfields. Journal of Spacecraft and Rockets, Vol. 29, No.2.

Hama, Francis A. (1966): Experimental Investigations of Wedge Base Pressure and Lip Shock. Tech. Rep. No. 32-1033 (Contract No. NAS7-100), Jet Propulsion Lab., California Inst. of Technology.

Holden, M. S.; Chadwick, K. M.; Gallis, M. A., and Harvey, J. K. (1995): Comparison Between Shock Tunnel Measurements On A Planetary Probe Configuration and DSMC Predictions. Proceedings of the 20th Int. Sym. on Shock Waves, July 2328, Pasadena, CA.

Hollis, Brian R. (1995): User's Manual for the One-Dimensional Experimental Hypersonic (1DHEAT) Data Reduction Code. NASA CR 4691, (Grant Nos. NAG1-1663, NAGW-1331).

Hollis, B. R. and Perkins, J. N. (1995): Hypervelocity Aeroheating Measurements in Wake of Mars Mission Entry Vehicle. AIAA 26th Fluid Dynamics Conference, June 19-22, San Diego, CA, AIAA-952314.

Hollis, Brian R. (1996): Experimental and Computational Aerothermodynamics of a Mars Entry Vehicle. Phd Dissertation, North Carolina State University. (Grant Nos. NAG1-1663, NAGW-1331).

Horvath, T. J.; McGinley, C. B.; and Hannemann, K. (1996): Blunt Body Near Wake Flow Field at Mach 6. 27th Fluid Dynamics Conference, June 18-20, New Orleans, LA, AIAA-1935.

Jones, Jim J. (1987): The Rationale for an Aeroassist Flight Experiment. AIAA 22th Thermophysics Conference, June 8-10, Honolulu, HI, AIAA-87-1508.

Kidd, C. T.; Nelson, C. G.; and Scott, W. T. (1995): Extraneous Thermoelectric EMF Effects Resulting From The Press-Fit Installation Of Coaxial Thermocouples in
Metal Models. AEDC Rep. No. , AAFB, TN.

Kastell, D.; Horvath T. J.; and Eitelberg G. (1994): Nonequilibrium Flow Expansion Around a Blunted Cone. 2nd European Symposium on Aerothermodynamics for Space Vehicles, Norwijk, NL.

Kastell, D.; Hannemann K.; Eitelberg G.; and Horvath T. J. (1995): Recompression of Nonequilibrium Flow in the Wake of a Blunted Cone. Proceedings of the 20th Int. Sym. on Shock Waves, July 23-28, Pasadena, CA.

Kendall, D. N.; Dixon, W. P.; and Schulte, E. H. (1967): Semiconductor Surface Thermocouples for Determining HeatTransfer Rates. IEEE Transactions on Aerospace and Electronic Systems, Vol AES-3, No. 4.

Kurotaki, T. (1996): Numerical Analysis of Thermochemical Nonequilibrium Hypersonic Flow Around Blunt Body. Proceedings of the 13th NAL Symposium on Aircraft Computational Aerodynamics, High Enthalpy Flow Workshop. SP-29, Tokyo.

Laurien E. (1995): Numerical Investigation of Laminar-Turbulent Transition in the Boundary-Layer of Reentry Capsules. AIAA 33rd Aerospace Sciences Meeting, January 9-12, Reno, NV, AIAA-95-0775.

Lees, L. (1964): Hypersonic Wakes and Trails. AIAA Journal, vol. 2, no. 3, pp.417-428.

Macaraeg, M. G. and Streett, C. L. (1991): Linear Stability of High-Speed Mixing Layers. Applied Numerical Mathematics, Vol. 7.

Mitcheltree, Robert A. (1994): Aerothermodynamic Methods for a Mars Environmental Survey Mars Entry. Journal of Spacecraft and Rockets, Vol. 31 , No. 3

Mitcheltree, Robert A. (1995): Computational Aerothermodynamics for Mars Pathfinder Including Turbulence. AIAA Atmospheric 
Flight Mechanics Conference, August 9, Baltimore, MD, AIAA-95-3493.

Miller, Charles G. III (1992): Hypersonic Aerodynamic/Aerothermodynamic Testing Capabilities at Langley Research Center. AIAA 17th Aerospace Ground Testing Conference, July 6-8, Nashville, TN, AIAA-92-3937.

Miller, Charles G. III (1981): Comparison of Thin-Film Resistance Heat-Transfer Gages With Thin-Skin Transient Calorimeter Gages in Conventional Hypersonic Wind Tunnels. NASA TM 83197.

Moss, J. N.; Price, J. M.; and Dogra, V. K. (1995): DSMC Calculations for a $70^{\circ}$ Blunted Cone at $3.2 \mathrm{~km} / \mathrm{s}$ in Nitrogen. NASA TM 109181.

Naysmith, A. (1961): Measurements of Heat Transfer in Bubbles of Separated Flow in Supersonic Air Streams. ASME \& Instn. Mech. Engrs., Int. Heat Transfer Conf., Part II, London.

Reddy, N. M. and Miller, C. G. (1986): Study of Heating Distributions on a Family of Very Large Angle Cones. Unpublished NASA report.

Riedelbauch, S. and Brenner, G. (1990): Numerical Simulation of Laminar Hypersonic Flow Past Blunt Bodies Including High Temperature Effects. AIAA 21st Fluid Dynamics and Lasers Conference, Seattle, Washington, AIAA 90-1492.

Roe, P. L. (1981): Approximate Riemann Solvers, Parameter Vectors, and Difference Schemes. J. Comp. Physics, Vol. 43, pp. 357-372.

Ronzheimer, A.; Brodersen, O.; Rudnik, R.; Findling, A.; and Rossow, C. (1994): A New Interactive Tool for the Management of Grid Generation Processes Around Arbitrary Configurations. 4th International Conference on Numerical Grid Generation in Computational Fluid
Dynamics and Related Fields, Swansea UK, April 6-8.

Rosenhauer, M.; Wollenhaupt, M.; Scheer, M.; and Beck, W. H. (1994): LIF Measurements in the Wake of A Blunt Body In HEG. 2nd European Symposium on Aerothermodynamics for Space Vehicles, Norwijk, NL.

Saric, W. S. et al. (1996): Hypersonic Experimental and Computational Capability, Improvement and Validation. AGARD-AR-319 Vol 1.

Shimshi, J. P. (1992): An Investigation of Aerodynamic Heating to Spherically Blunted Cones at Angle of Attack. M.S. Thesis, George Washington University.

Stewart, D. A. and Chen, Y. K. (1993): Convective Heat Transfer Rate Distributions Over a $140^{\circ}$ Blunt Cone at Hypersonic Speeds in Different Gas Environments. AIAA 93-2787.

Tauber, M., et. al. (1993): MESUR Probe Aerobrake Preliminary Design Study. Journal of Spacecraft and Rockets, Vol. 30, No.4 .

Thornton, Aimee D. (1993): A Computational and Analytical Investigation of High Total-Enthalpy Supersonic Shear-Layer Data. MS Thesis, The George Washington University.

Wells, William L. (1990): Surface Flow and Heating Distributions on a Cylinder in Near Wake of Aeroassist Flight Experiment (AFE) Configuration at Incidence in Mach 10 Air. NASA TP 2954.

Wieting, Allan R. (1987): Experimental Study of Shock Wave Interference Heating on a Cylindrical Leading Edge. NASA TM 100484.

Yee, H. C. and Harten, A. (1987): Implicit TVD Schemes for Hyperbolic Conservation Laws in Curvilinear Coordinates. AIAA Journal Vol. 25, pp. 266-274. 
Table 1. Nominal Flow Conditions

\begin{tabular}{|l|l|l|l|}
\hline $\mathrm{Re}_{\infty, \mathrm{d}}$ & $0.25 \times 10^{6}$ & $0.5 \times 10^{6}$ & $1 \times 10^{6}$ \\
\hline $\mathrm{P}_{\mathrm{t}, 1}\left(\mathrm{~N} / \mathrm{m}^{2}\right)$ & $2.406 \times 10^{6}$ & $4.998 \times 10^{6}$ & $9.783 \times 10^{6}$ \\
\hline $\mathrm{T}_{\mathrm{t}, 1}\left({ }^{\circ} \mathrm{K}\right)$ & 1005 & 1003 & 1013 \\
\hline$\rho_{\infty}\left(\mathrm{kg} / \mathrm{m}^{3}\right)$ & $4.471 \times 10^{-3}$ & $8.799 \times 10^{-3}$ & $16.13 \times 10^{-3}$ \\
\hline $\mathrm{T}_{\infty}\left({ }^{\circ} \mathrm{K}\right)$ & 53.15 & 51.86 & 51.27 \\
\hline $\mathrm{u}_{\infty}(\mathrm{m} / \mathrm{sec})$ & 1415 & 1415 & 1426 \\
\hline $\mathrm{M}_{\infty}$ & 9.674 & 9.791 & 9.925 \\
\hline$\gamma_{\infty}$ & 1.402 & 1.402 & 1.402 \\
\hline$\rho 2 / \rho_{\infty}$ & 5.968 & 5.974 & 5.990 \\
\hline $\mathrm{Re}_{2, \mathrm{~d}}$ & $0.023 \times 10^{6}$ & $0.046 \times 10^{6}$ & $0.084 \times 10^{6}$ \\
\hline
\end{tabular}




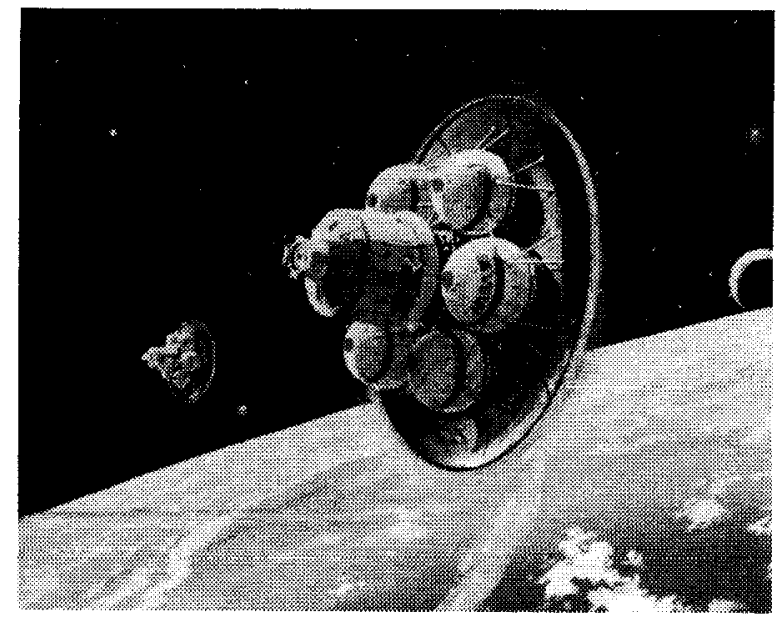

Fig. 1 Conceptual drawing of an aerobraking vehicle.

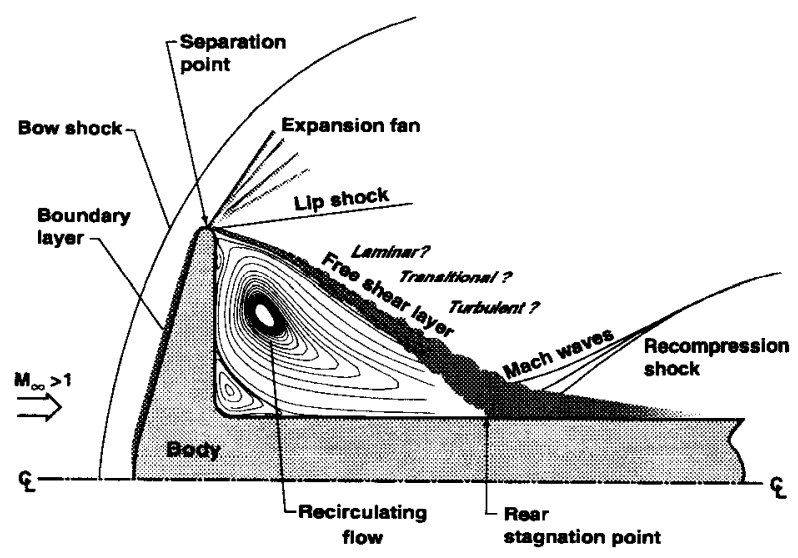

Fig. 2. Schematic representation of the flow region behind a blunt body in hypersonic flow.

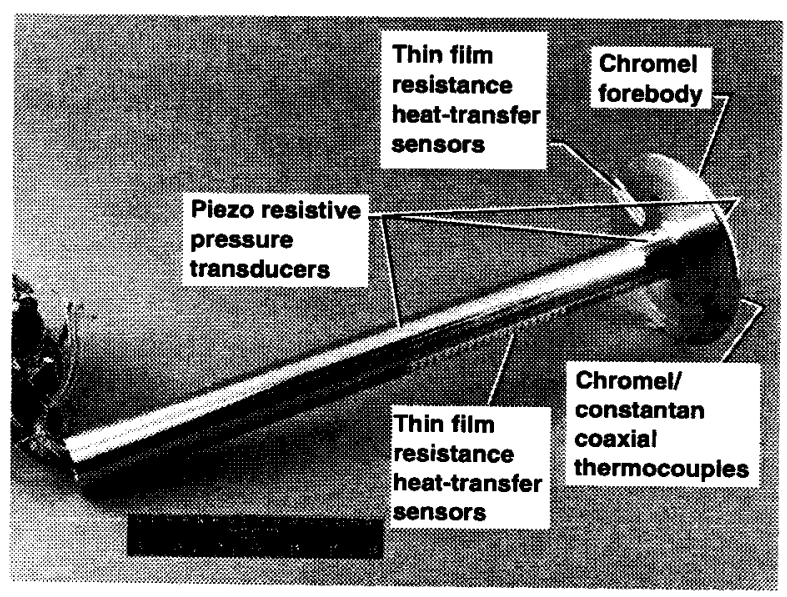

Fig. 3. Photograph of instrumented $70^{\circ}$ blunted cone heat transfer model.

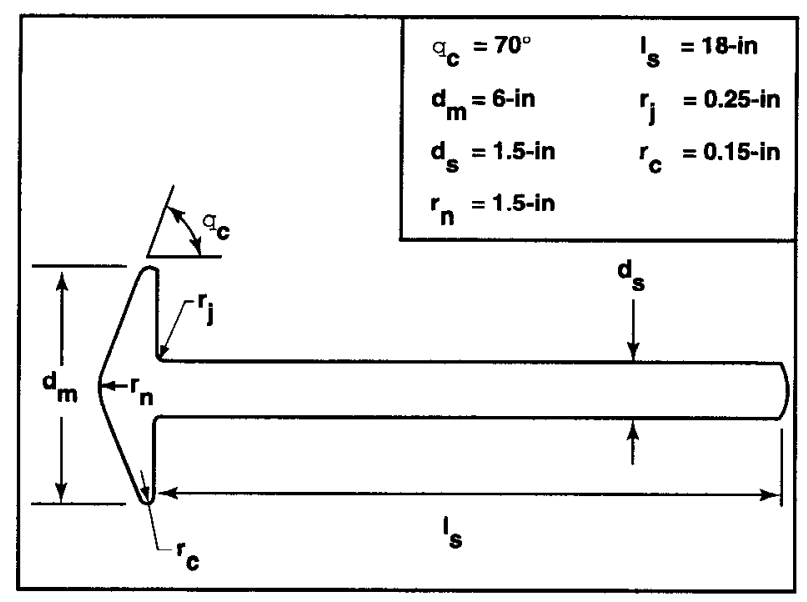

Fig. 4. Dimensional sketch of $70^{\circ}$ blunted cone model.

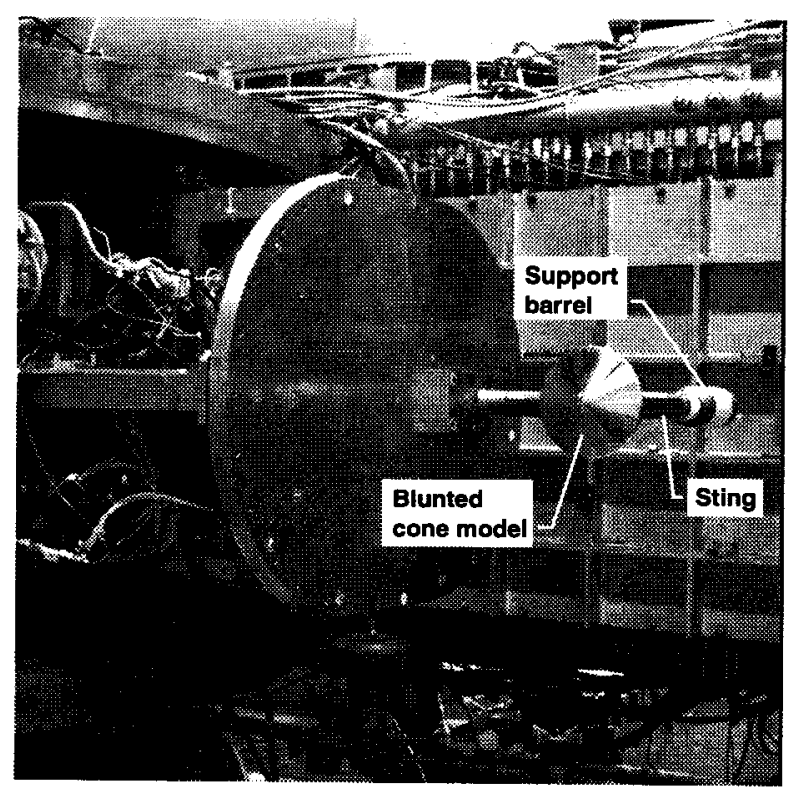

Fig. 5. Blunted cone installed in 31-Inch Mach 10 Tunnel. 


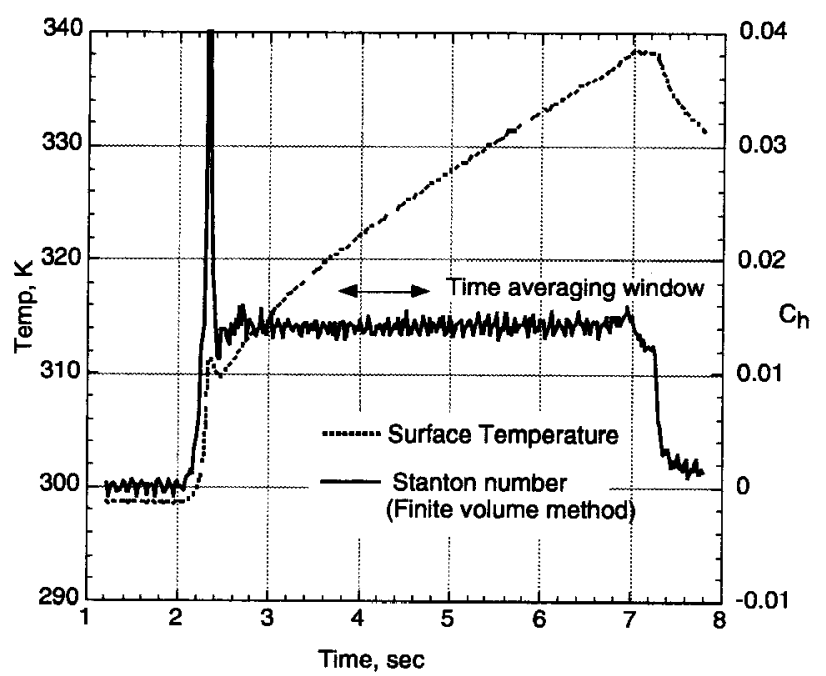

(a) Forebody stagnation point thermocouple

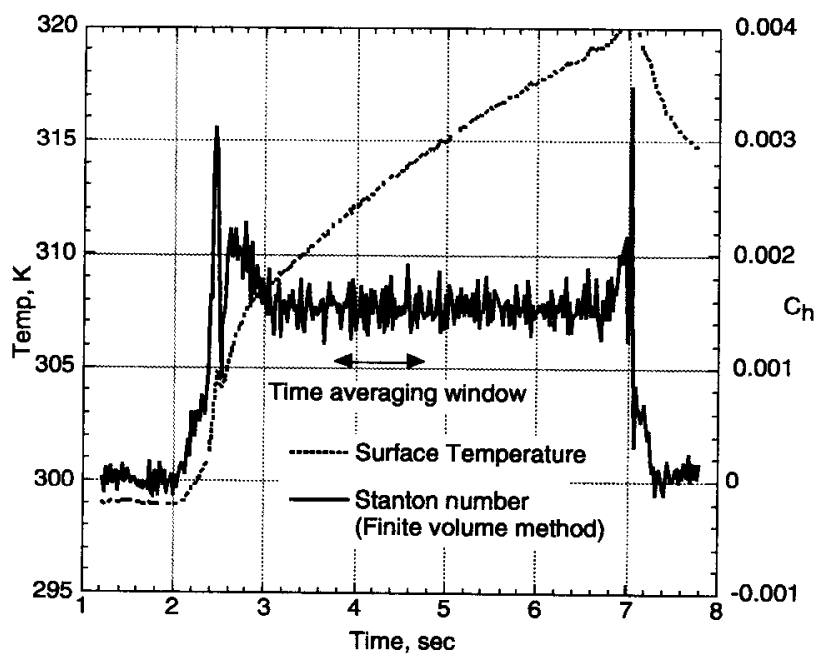

(b) Sting thin film gage

Fig. 6. Temperature and Stanton number time history.

$$
M_{\infty}=10, \operatorname{Re}_{\infty, \mathrm{d}}=0.5 \times 10^{6}, \alpha=0 \mathrm{deg} .
$$

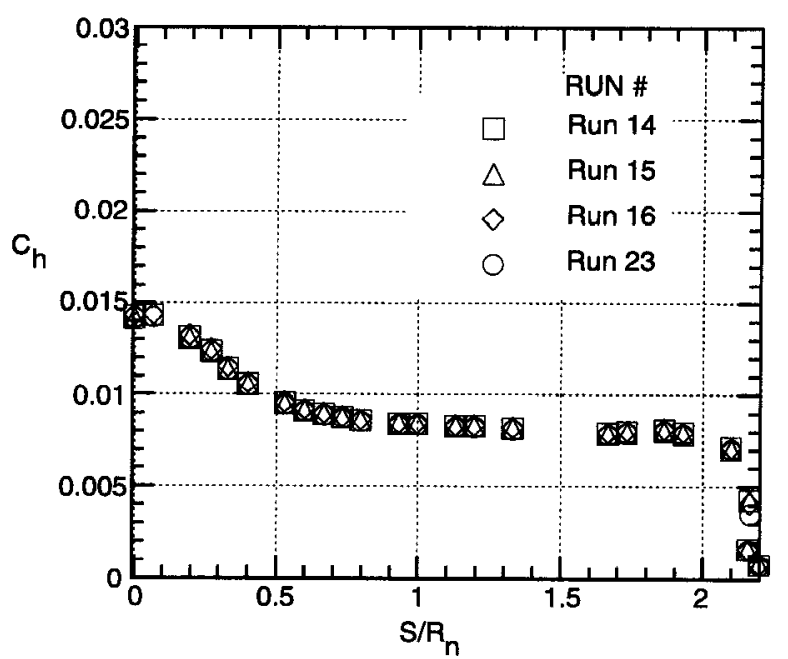

(a) Forebody

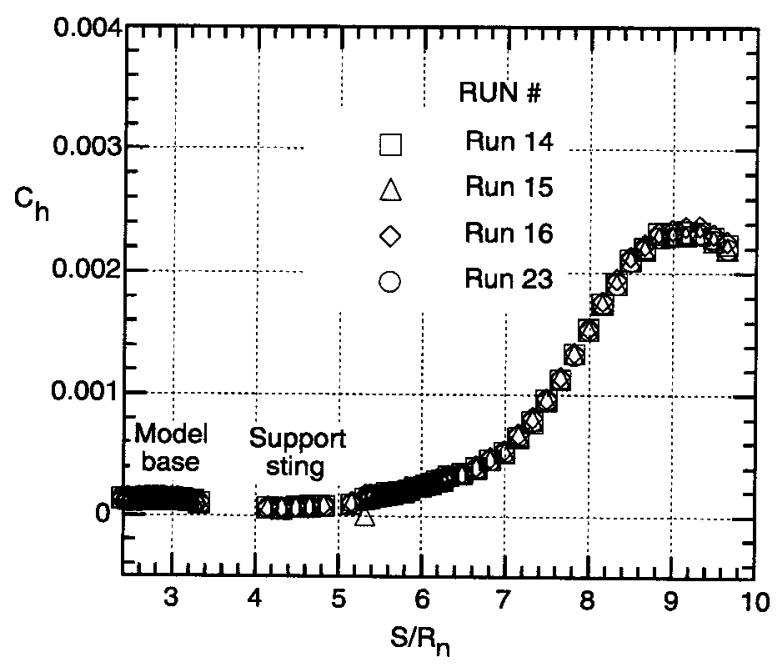

(b) Base-sting

Fig. 7. Repeatability of Stanton number heating distribution.

$M_{\infty}=10, \operatorname{Re}_{\infty, \mathrm{d}}=0.5 \times 10^{6}, \alpha=0 \mathrm{deg}$. 


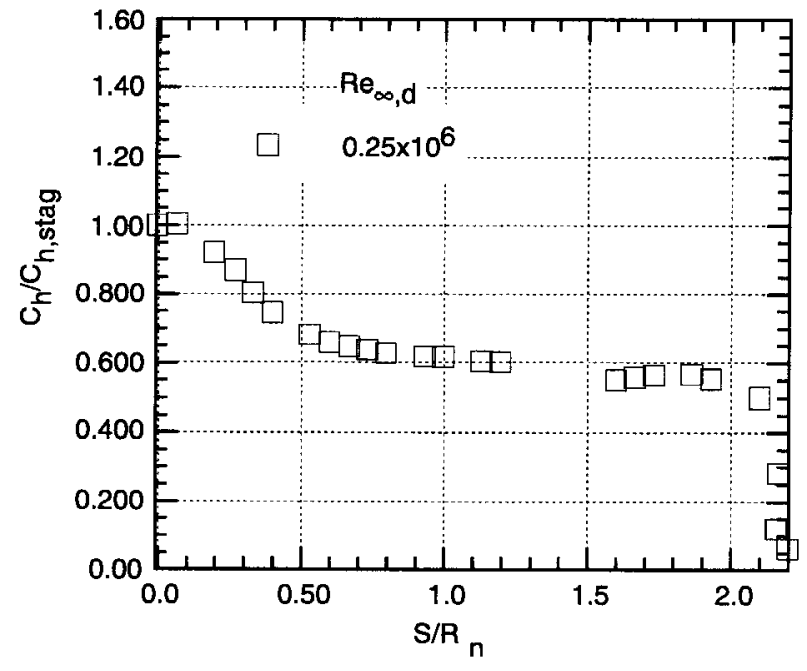

(a) Forebody

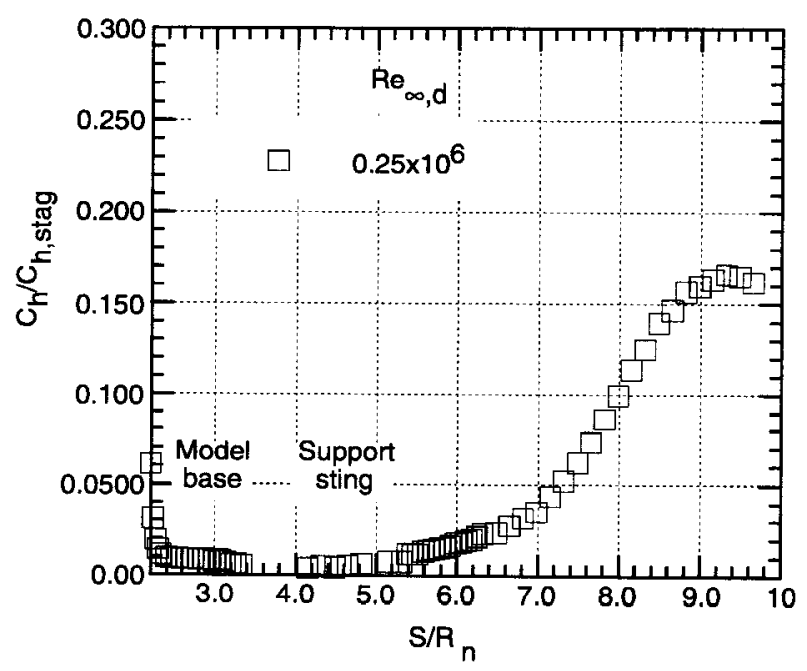

(b) Base-sting

Fig. 8. Normalized Stanton number heating distribution.

$M_{\infty}=10, \operatorname{Re}_{\infty, \mathrm{d}}=0.25 \times 10^{6}, \alpha=0 \mathrm{deg}$

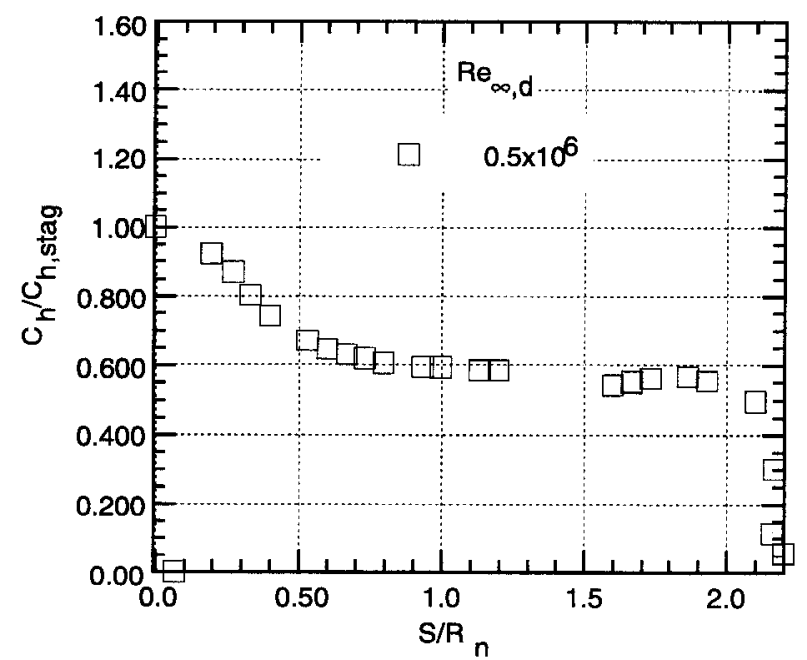

(a) Forebody

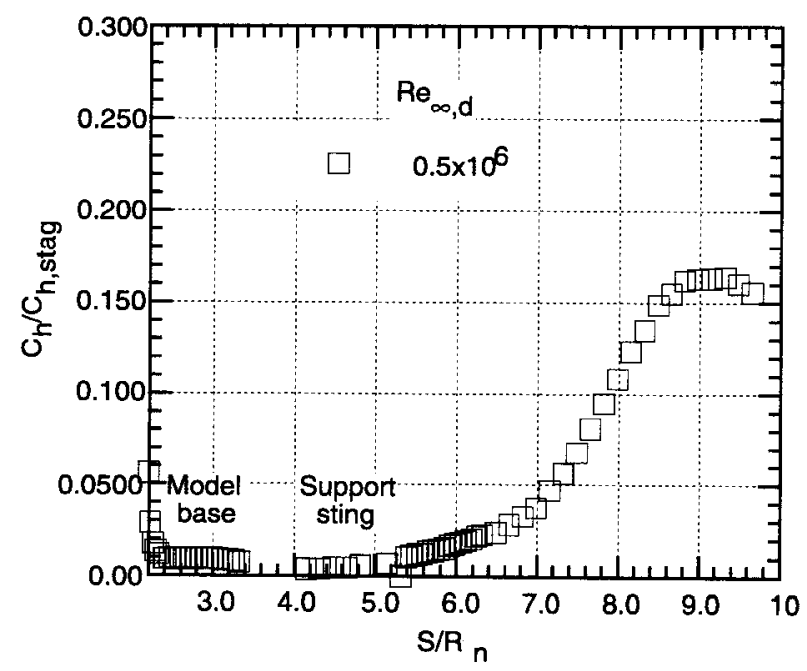

(b) Base-sting

Fig 9. Normalized Stanton number heating distribution.

$M_{\infty}=10, \operatorname{Re}_{\infty, \mathrm{d}}=0.5 \times 10^{6}, \alpha=0 \mathrm{deg}$. 


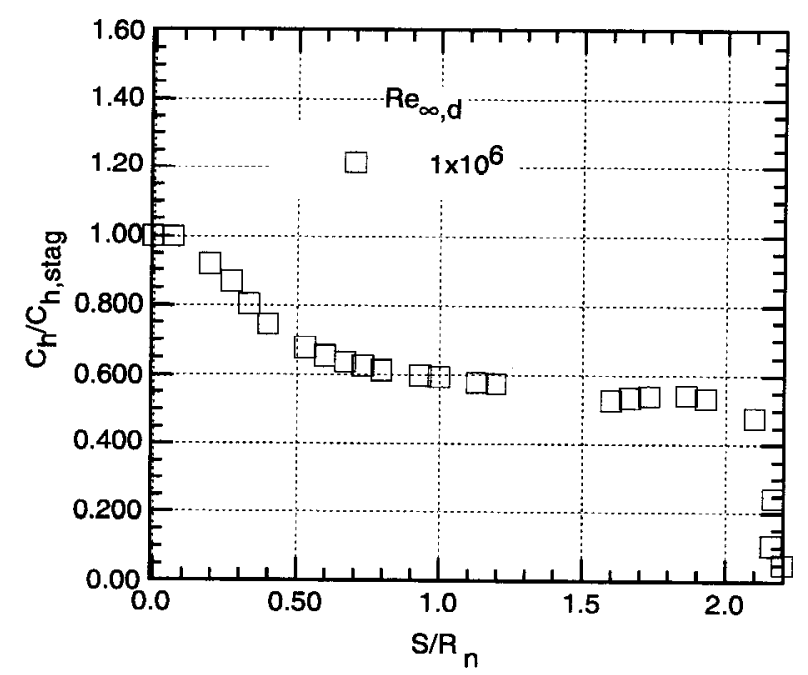

(a) Forebody

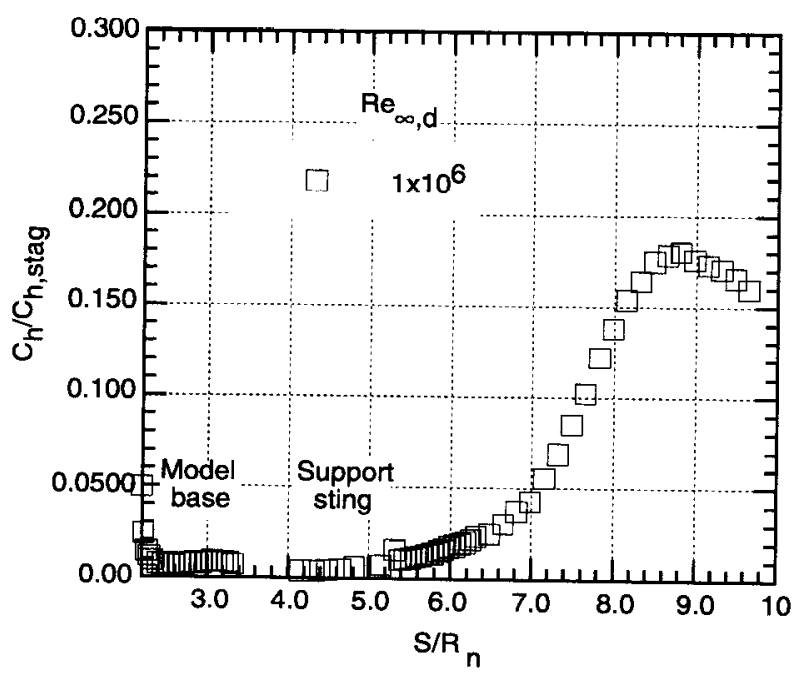

(b) Base-sting

Fig 10. Normalized Stanton number heating distribution.

$M_{\infty}=10, \operatorname{Re}_{\infty, d}=1 \times 10^{6}, \alpha=0$ deg.

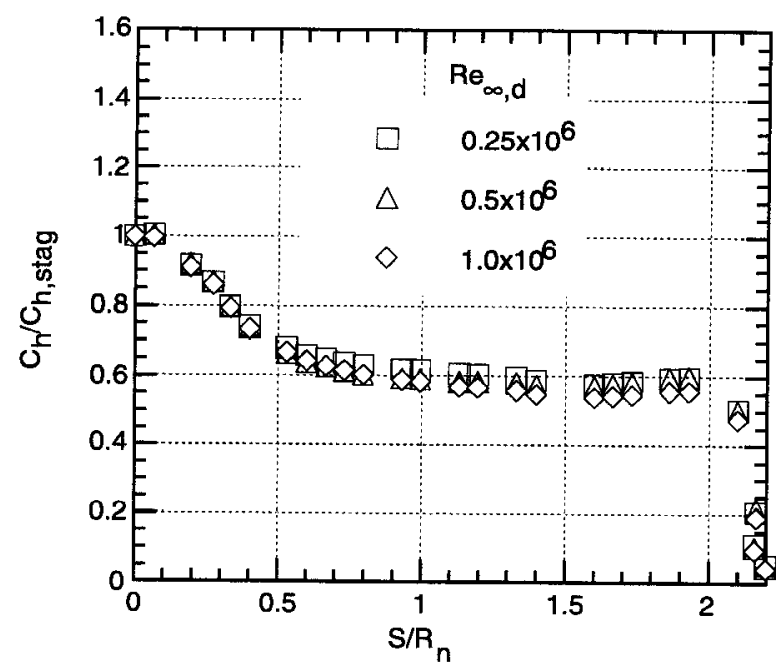

(a) Forebody

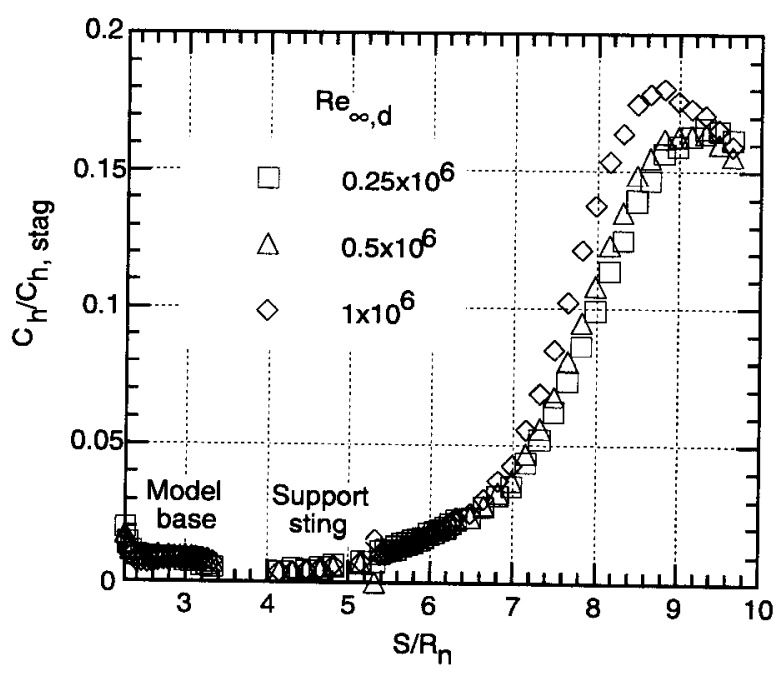

(b) Base-sting

Fig 11. Effect of Reynolds number on normalized

Stanton number heating distribution.

$$
\mathrm{M}_{\infty}=10, \alpha=0 \mathrm{deg} .
$$




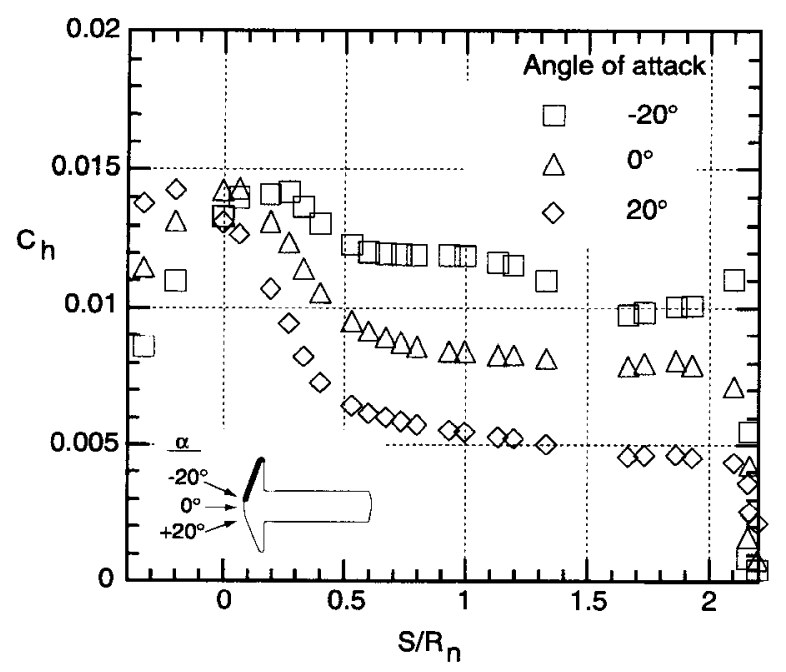

(a) Forebody

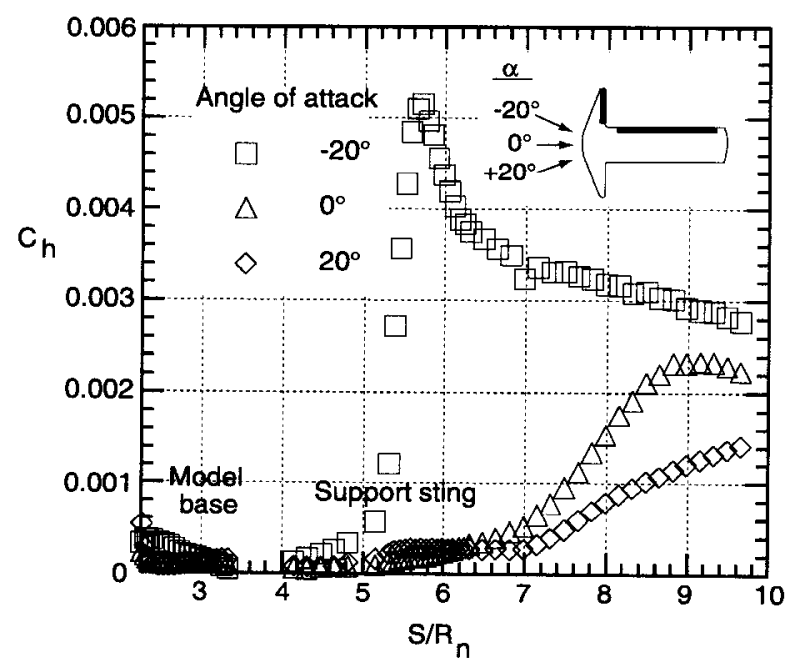

(b) Base-sting

Fig 12. Effect of angle-of-attack on normalized

Stanton number heating distribution.

$$
M_{\infty}=10, \operatorname{Re}_{\infty, \mathrm{d}}=0.5 \times 10^{6}
$$

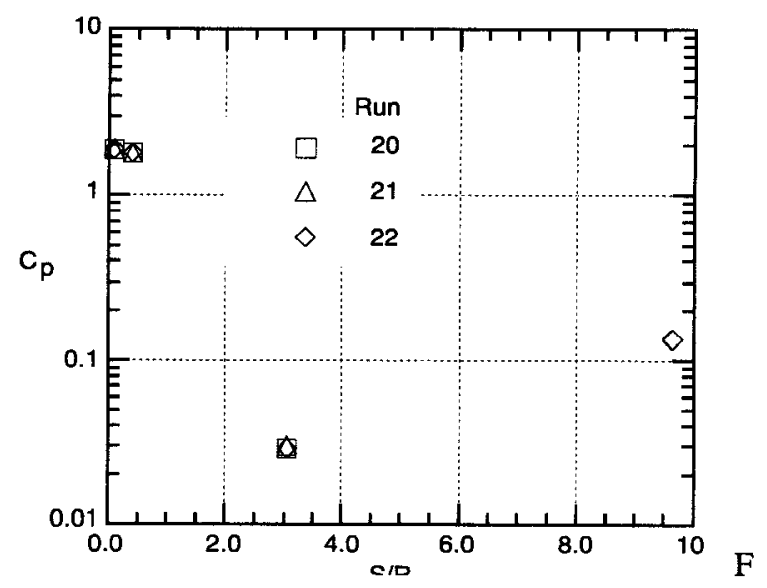

ig. 13. Repeatabitity of measured surface pressures coefficient.

$$
M_{\infty}=10, \operatorname{Re}_{\infty, \mathrm{d}}=1 \times 10^{6}, \alpha=0 \mathrm{deg} .
$$

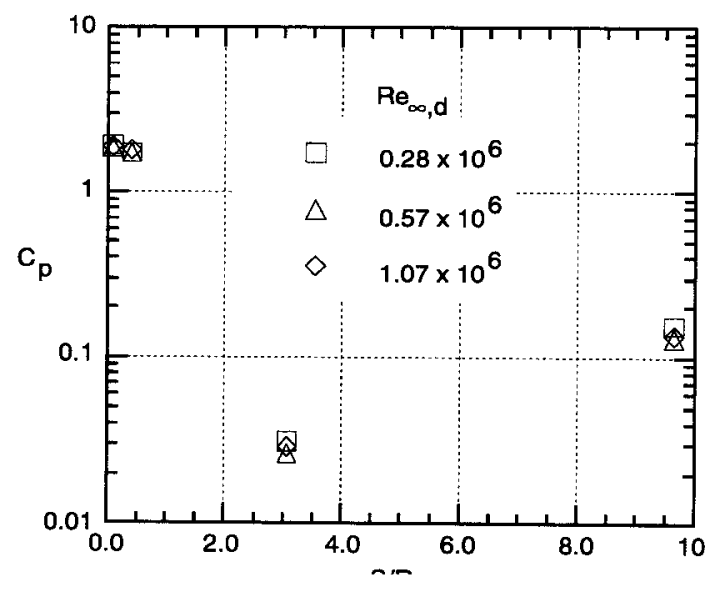

Fig. 14. Effect of Reynolds number on surface pressure coefficient. $M_{\infty}=10, \alpha=0 \mathrm{deg}$.

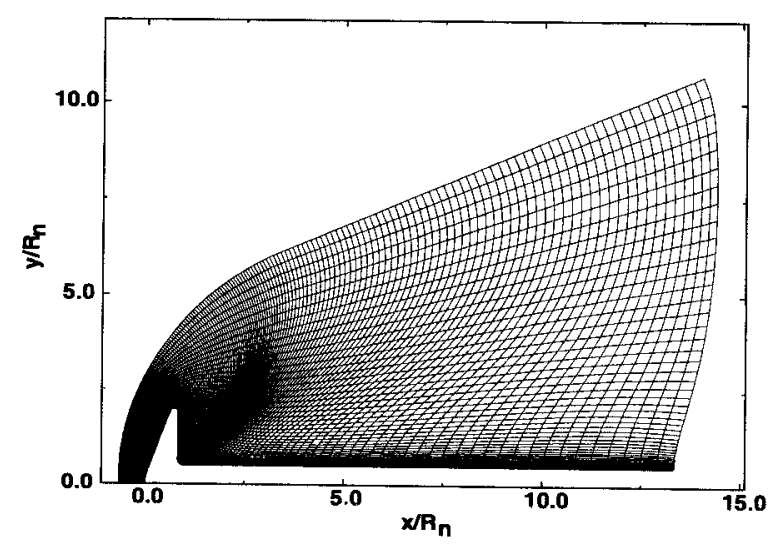

Fig. 15. Computational grid for NS code simulation of blunt body flow. Mesh size 193 x 76 . 


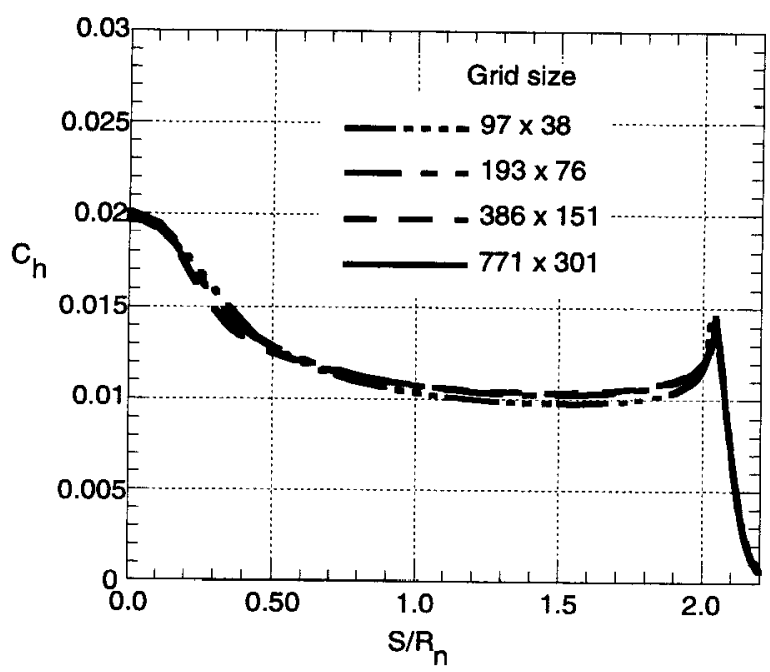

(a ) Forebody

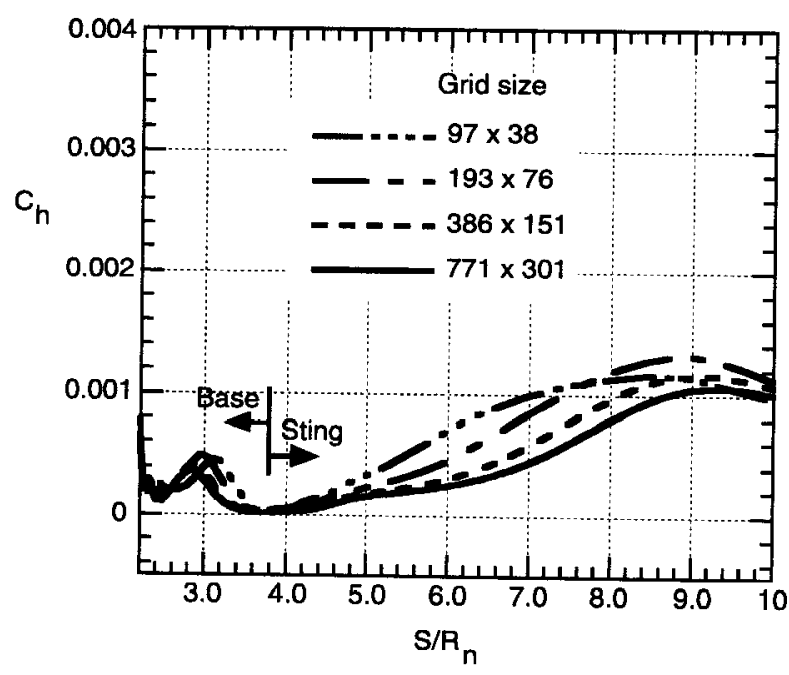

(b) Base-sting

Fig 16. Effect of grid refinement on predicted laminar Stanton number heating distribution.

$$
M_{\infty}=10, \operatorname{Re}_{\infty, \mathrm{d}}=2.8 \times 10^{6}
$$
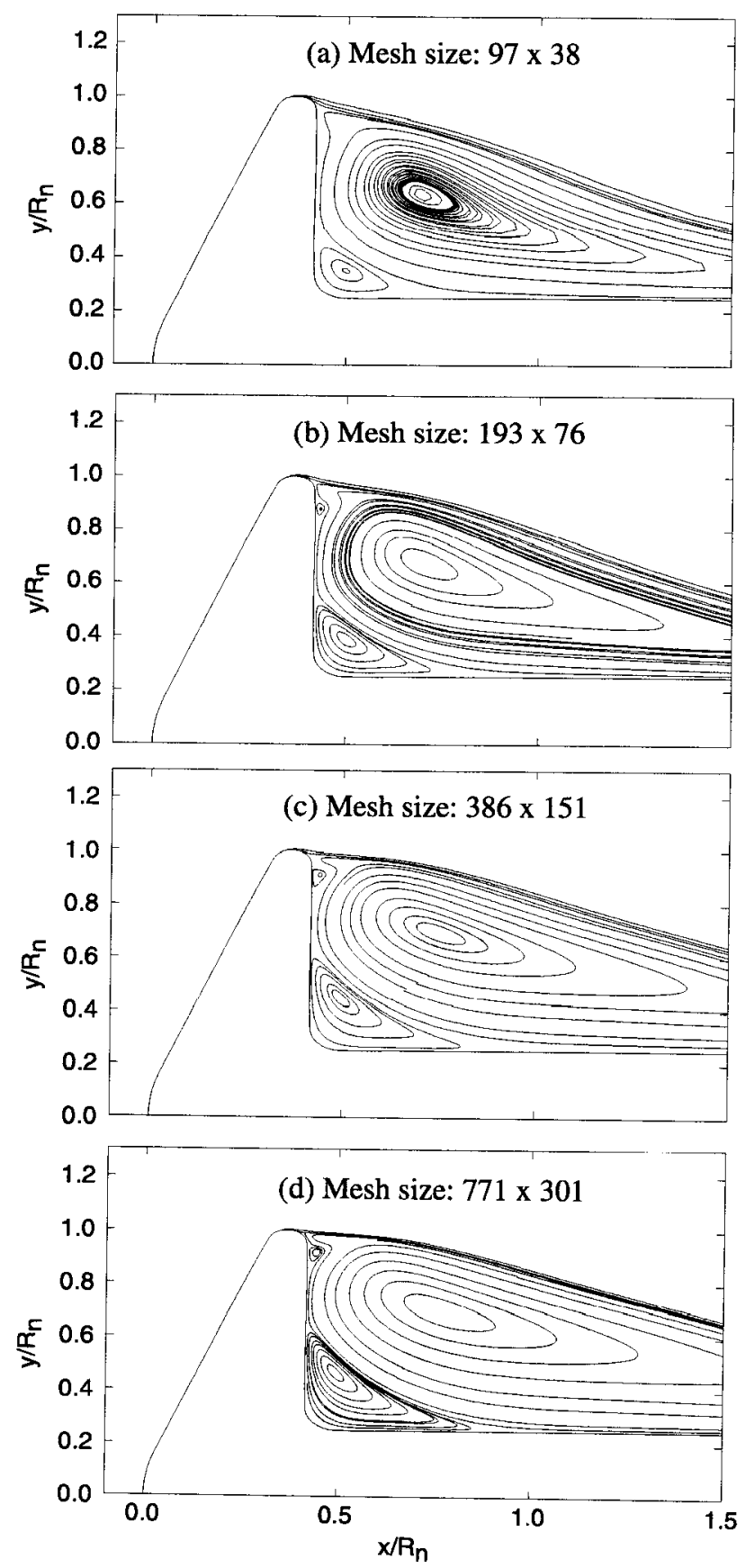

Fig 17. Particle paths for laminar computational wake flowfield. $M_{\infty}=10, \operatorname{Re}_{\infty, \mathrm{d}}=0.28 \times 10^{6}, \alpha=0 \mathrm{deg}$. 


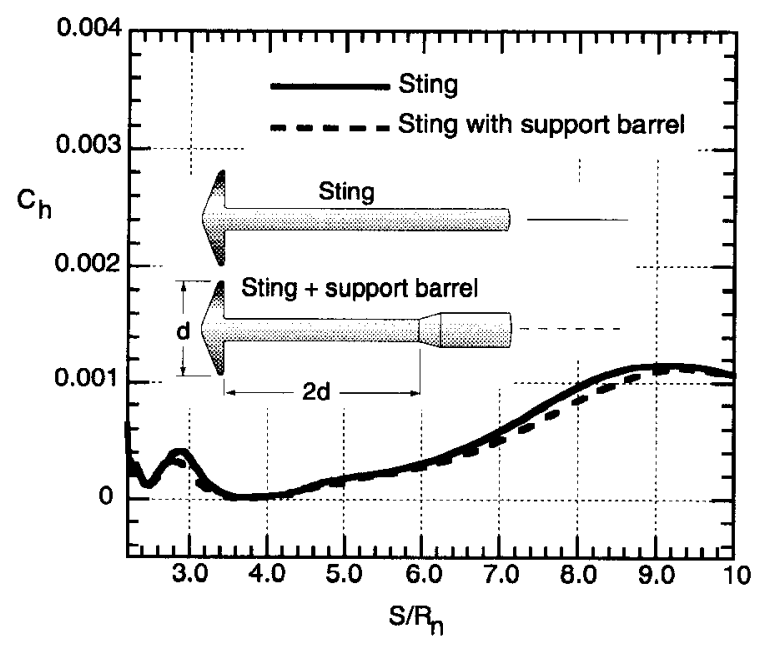

Fig 18. Effect of model support system of predicted laminar base-sting Stanton number haeting distribution.

$M_{\infty}=10, \operatorname{Re}_{\infty, d}=0.28 \times 10^{6}, \alpha=0$ deg.

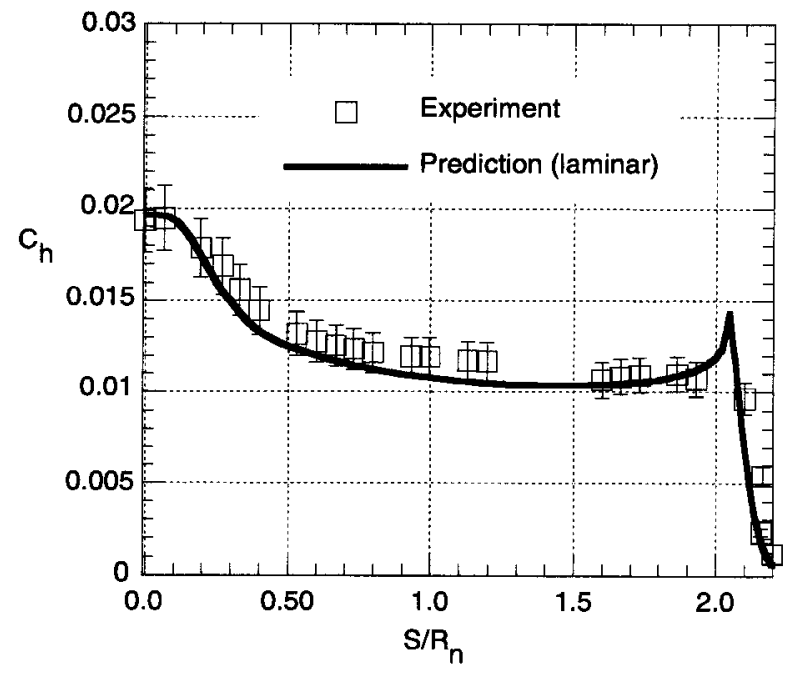

(a) Forebody

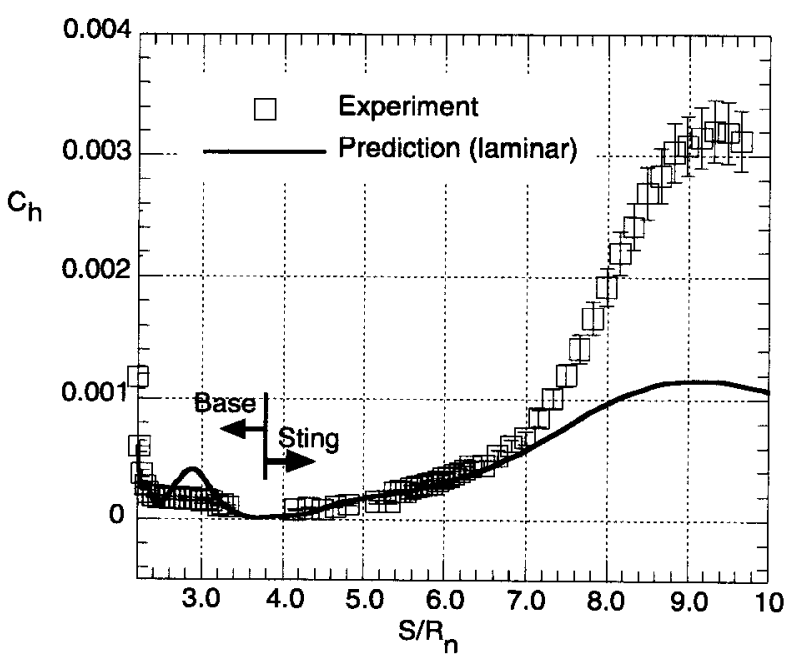

(b) Base-sting

Fig. 19. Comparison of measured Stanton number with laminar prediction.

$M_{\infty}=10, \operatorname{Re}_{\infty, d}=0.28 \times 10^{6}, \alpha=0$ deg. 


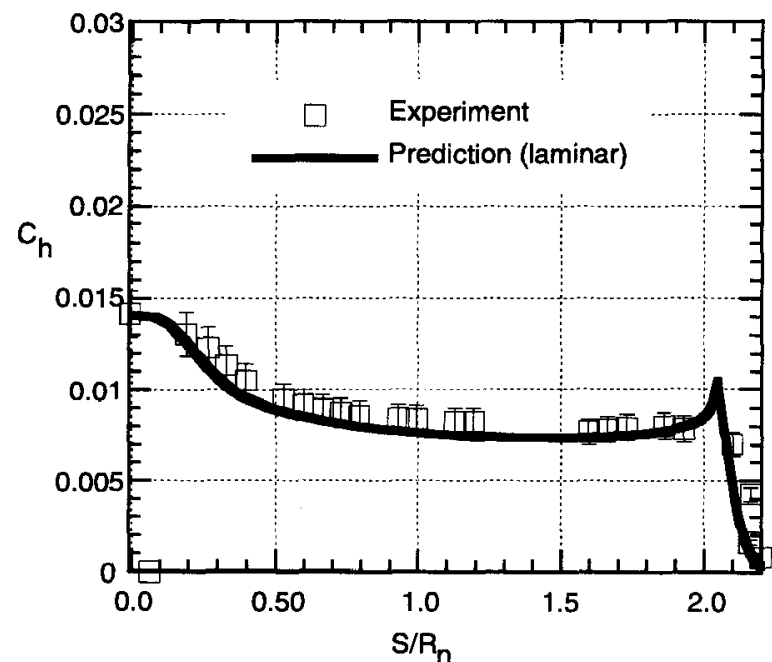

(a) Forebody

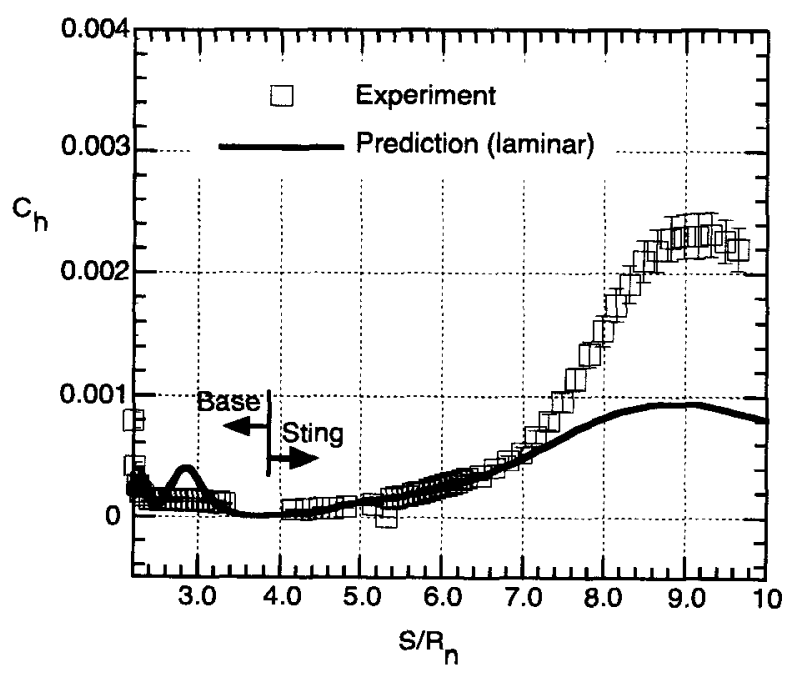

(b) Base-sting

Fig. 20 Comparison of measured Stanton number with laminar prediction.

$M_{\infty}=10, \operatorname{Re}_{\infty, d}=0.57 \times 10^{6}, \alpha=0 \mathrm{deg}$.

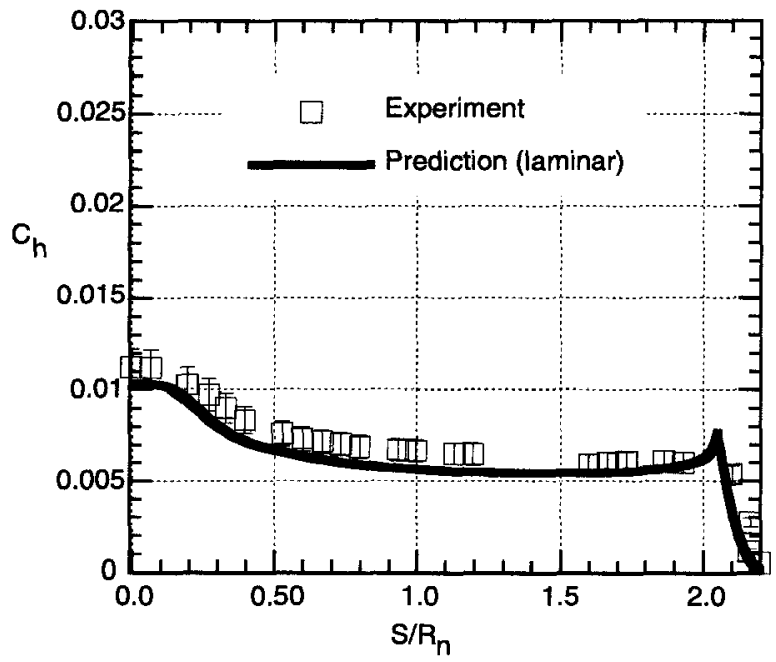

(a) Forebody

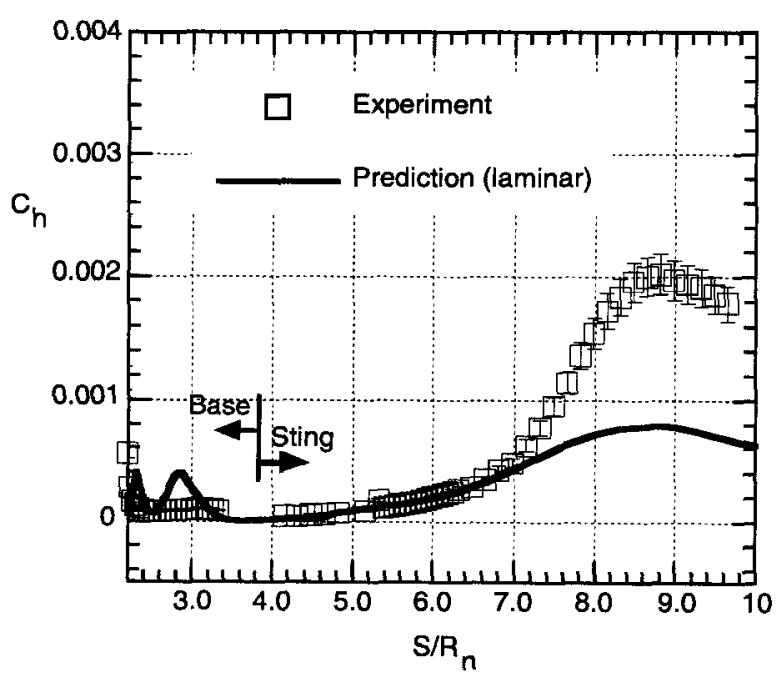

(b) Base-sting

Fig. 21 Comparison of measured Stanton number with laminar prediction.

$M_{\infty}=10, \operatorname{Re}_{\infty, d}=1.07 \times 10^{6}, \alpha=0 \mathrm{deg}$. 


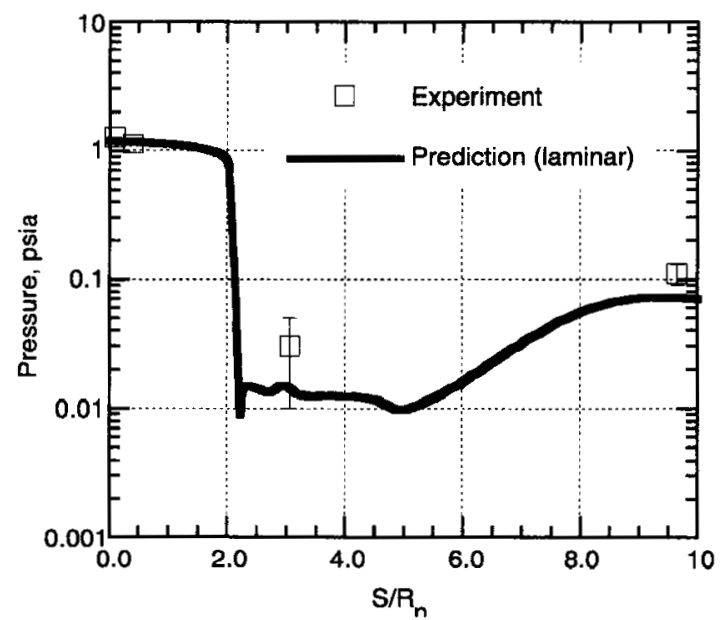

(a) $\mathrm{Re}_{\infty, \mathrm{d}}=0.28 \times 10^{6}$

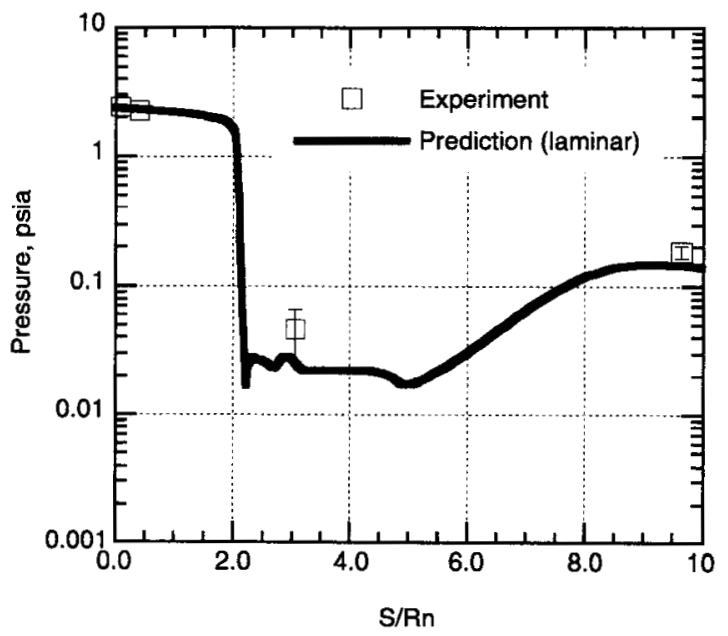

(b) $\operatorname{Re}_{\infty, \mathrm{d}}=0.57 \times 10^{6}$

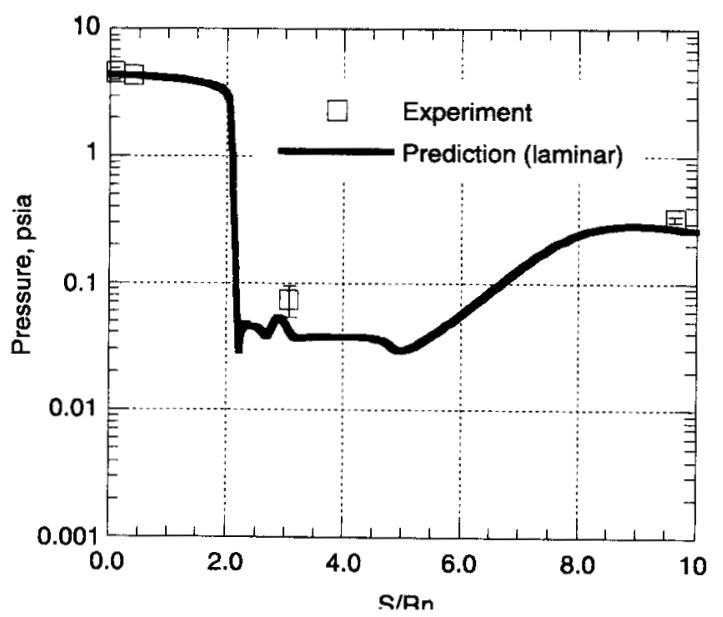

(c) $\operatorname{Re}_{\infty, \mathrm{d}}=1.07 \times 10^{6}$

Fig. 22 Comparison of measured surface pressure with laminar prediction. $M_{\infty}=10, \alpha=0$ deg. 